\title{
Public real estate and the term structure of interest rates: a cross-country study
}

Article

Accepted Version

Akimov, A., Stevenson, S. and Zagonov, M. (2015) Public real estate and the term structure of interest rates: a cross-country study. Journal of Real Estate Finance and Economics, 51 (4). pp. 503-540. ISSN 1573-045X doi:

https://doi.org/10.1007/s11146-014-9492-x Available at https://centaur.reading.ac.uk/40907/

It is advisable to refer to the publisher's version if you intend to cite from the work. See Guidance on citing.

To link to this article DOI: http://dx.doi.org/10.1007/s11146-014-9492-x

Publisher: Springer

All outputs in CentAUR are protected by Intellectual Property Rights law, including copyright law. Copyright and IPR is retained by the creators or other copyright holders. Terms and conditions for use of this material are defined in the End User Agreement.

\section{www.reading.ac.uk/centaur}

\section{CentAUR}

Central Archive at the University of Reading 
Reading's research outputs online 


\section{Henley \\ Business School}

UNIVERSITY OF READING

\section{Listed Real Estate Markets and the Term Structure of Interest Rates: A Cross-Country Study}

Accepted for publication in Journal of Real Estate Finance and Economics
Alexey Akimov (Lancaster University), Simon Stevenson (University of Reading) \& Maxim Zagonov (University of Toulouse) 


\title{
Listed Real Estate Markets and the Term Structure of Interest Rates: A Cross-Country Study
}

\author{
Alexey Akimov \\ Lancaster University Management School \\ Corresponding author. Department of Accounting \& Finance, \\ Management School, Lancaster University, Bailrigg, Lancaster, LA1 \\ 4YX, United Kingdom. E-mail address: a.akimov@lancaster.ac.uk.

\section{Simon Stevenson} \\ Henley Business School, University of Reading \\ (E-mail address: s.a.stevenson@ reading.ac.uk)
}

\section{Maxim Zagonov}

Toulouse Business School, University of Toulouse

(E-mail address: m.zagonov@tbs-education.fr) 


\title{
Listed Real Estate Markets and the Term Structure of Interest Rates: A Cross-Country Study*
}

\begin{abstract}
:
Using a variation of the Nelson-Siegel term structure model we examine the sensitivity of real estate securities in six key global markets to unexpected changes in the level, slop and curvature of the yield curve. Our results confirm the time-sensitive nature of the exposure and sensitivity to interest rates and highlight the importance of considering the entire term structure of interest rates. One issue that is of particular of interest is that despite the 2007-9 financial crisis the importance of unanticipated interest rate risk weakens post 2003. Although the analysis does examine a range of markets the empirical analysis is unable to provide definitive evidence as to whether REIT and property-company markets display heightened or reduced exposure.
\end{abstract}

Keywords securitised real estate, interest rate risk, yield curve modeling

\footnotetext{
* The authors greatly appreciate the comments of the anonymous referees whose comments substantially improved the paper.
} 


\section{Listed Real Estate Markets and the Term Structure of Interest Rates: A Cross-Country Study}

\section{Introduction}

The events of the last decade have brought into sharp focus the importance of the credit markets and how interest rates dynamics can feed through and impact asset classes such as equities. In a general context, Bernanke \& Kuttner (2005) argue that changes in interest rates can affect stock prices in three primary ways, namely; the impact on expected future dividends, changes in the discount rate and changes in the equity risk premium. Much of the early literature examined the overall equity market, or if sector specific tended to concentrate on financial institutions ${ }^{\mathrm{i}}$. However, in recent years been an increasing number of papers that have specifically considered and analyzed listed real estate securities such as REITs (Real Estate Investment Trusts). The corporate structure of listed real estate firms, together with their underlying portfolios of real assets, provides an ideal forum to consider the sensitivity of asset prices to changes in interest rates. This is due to the multiple channels through which changes in interest rates can impact the operating, financial and share price performance of the firms.

As a real asset, property is affected by the performance of the underlying economy. Given the key macroeconomic role that interest rates have (Bernanke \& Blinder, 1992), changes in rates may, if of sufficient magnitude, result in direct consequences on the operating performance and cash flows of the firms. This may arise through the impact on occupational demand and all of the related issues that accompany this, such as rental growth, occupancy and vacancy rates, and thus the overall income of the firms. Conceptual and theoretical work, such as that of DiPasquale \& Wheaton (1992) and Fisher (1992) illustrate the inter-linkages between economic activity and the direct real estate market, whilst papers such as Ling \& Naranjo (1997), 
and numerous papers subsequently, have empirically demonstrated that interest rates may represent a systematic risk factor for real estate. Furthermore, interest rate risk can also be transmitted via the yields used to capitalise the income flows from the properties underlying the firms (Lizieri and Satchell, 1997) ${ }^{\mathrm{ii}}$.

There are further reasons why real estate firms may respond differently to changes in monetary policy compared to companies in other industries. One source of interest rate exposure lies with the high degree of debt financing generally used in the real estate market (Bredin et al. 2007). This is true not only for property companies but also for tax transparent vehicles such as REITs. Despite their tax efficiency REITs often continue to employ substantial amounts of debt due to being small firms, having higher costs of equity, for growth and expansion purposes and for the opportunities debt provides to participate in large scale projects (e.g. Jaffe, 1991, Chan et al., 2003; Ooi et al., 2010). Accordingly, due to their extensive use of debt, unexpected interest rate fluctuations will affect the firms cost of finance and market values. In addition, the use of leverage alters a company's cost-of-capital and therefore can affect the future availability of external debt facilities. Subsequent interest rate changes and the interactions between firms' investment and financing activities may therefore be reflected in a company's share price (Bernanke \& Gertler, 1995). Another reason for the potentially heightened exposure of real estate stocks to interest rates is specific to the REIT sector and is concerned with the minimum mandatory dividend payment. Given the high-yield status of REITs the impact of interest rate fluctuations on the present value of dividends is likely to be greater in a REIT context (Bernanke and Kuttner 2005).

Given the importance of interest rates, in both the specific context of listed real estate securities and in the broader setting of the underlying direct real estate market, this paper empirically address' the sensitivity of the public real estate markets to interest rate risk and 
specifically which interest rate factors are the most significant in terms of both returns and volatility.

The study differs from the previous literature in a number of respects. Firstly, unlike previous contributions to the literature we do not limit our analysis to consider the sensitivity to fluctuations in a single interest rate factor. Rather, we use a dynamic version of the NelsonSiegel model, which captures the dynamics of the entire term structure of interest rates with three latent factors that represent the level, slope, and curvature of the yield curve. Secondly, our study extends previous contributions by considering the sensitivity of real estate securities to unexpected interest rate movements. Previous studies in both the general finance and real estate specific literature, have largely considered actual changes in interest rates. However, studies such as Bredin et al. (2007, 2011) and Xu \& Yang (2011) illustrate the importance of considering unexpected changes when examining interest rate sensitivity. Finally, the paper extends a predominantly U.S. focused literature to examine six key real estate security markets, namely; Australia, Hong Kong, Japan, Singapore, the U.K. together with the U.S. These markets account for approximately $80 \%$ of investable listed real estate in terms of market capitalization and volume traded (Psaltis \& Chubb, 2008). This sample also has the advantage that it incorporates a mixture of regulatory structures. Two of the markets, Australia and the U.S., operate under a REIT regime throughout the entire sample period. The remaining markets have introduced a REIT structure during the time period considered in the study. However, the relative importance of REITs versus conventional property companies differs. For example, in Hong Kong the majority of firms, including the largest, have retained a corporate structure. In contrast, in the U.K. the majority of the large cap property companies converted to REIT status when it was introduced in 2007. It will therefore be of interest to see whether there are discernable 
differences in the empirical findings across the markets. Whilst differences may not be solely due to differences in the legal framework in place, it may play a role.

The results highlight that real estate securities are significantly exposed to interest rate fluctuations. However, the results are sensitive on the time period examined. One particular point of interest is that the importance of interest rate risk weakens in the most recent period, a timeframe which includes the 2007-2009 financial crisis. The empirical results obtained also do indicate that the differences in findings across previous papers may be in part due to the use of single interest rate proxies and the failure to model the entire term structure of interest rates. The remainder of the paper is structured as follows. The next section discuss some of the pertinent literature and in doing so presents the core underlying hypotheses to be considered in the paper. Section 3 details the data used in the empirical analysis and presents the detailed methodological framework adopted. Section 4 reports the main empirical results and also presents a number of robustness tests. The final section provides concluding comments and observations.

\section{Related Literature}

As noted in the introduction, there have been an increasing number of papers over the course of the last decade to have examined the sensitivity of listed real estate securities to interest rates. Although the exact methodological framework has differed across the papers there are some commonalities in the empirical results reported. A number of papers have reported that REITs are predominantly exposed to longer-term rates, for example Devaney (2001) finds heightened sensitivity to 10 -year government bond yields. Similar findings are also reported by Chen and Tzang (1988) and He et al. (2003). However, He et al. (2003) emphasise that their conclusions may be biased by the interest rate chosen. Against this background, Allen et al. (2000) report significant sensitivity of REITs to both short and long-term government bonds, as well as the stock market. They further argue that firms can adjust their exposure to the market by 
changing financial leverage, but not the exposure to interest rates. In a similar vein, Stevenson et al. (2007) use interest rate proxies of three maturities, the 1-month interbank rate together with 10 and 15-year government bond yields. Their analysis of U.K. property companies is conducted for a period characterised by historically low and stable interest rates, yet the authors report significant results for all of the interest rates used, although the coefficient on the short-term rate is of the unexpected positive sign. These findings are consistent with Lizieri \& Satchel (1997) who estimated the response of U.K. property stocks under two distinct regimes, finding that firms were particularly sensitive during the low interest rate period. In contrast, during the high interest rate regime real estate stocks experienced sharp falls in value, felt to reflect increased uncertainty. This time-varying nature of the sensitivity to interest rates is also found in a number of studies that have adopted a GARCH (Generalised Autoregressive Conditional Heteroskedasticity) framework to consider the impact on returns and volatility (e.g. Devaney, 2001; Stevenson et al., 2007). In addition, Liow et al. (2003) in their analysis of the Singaporean market, identify a systematic relationship with interest rate risk but note that the pricing of that risk is subject to market conditions.

In addition to the aforementioned studies there is also a strand of the literature that has adopted a different methodological approach, one that comes more from an asset pricing-factor model framework. Liang et al. (1995), for example, estimate a two-factor model that includes an interest rate variable and the overall stock market. They observe only weak sensitivity to government bond returns of different maturities. Studies such as Glascock et al. (2000) have observed a reduced sensitivity of U.S. Equity REITs to government bonds during what is often referred to as the "modern REIT era". Based on cointegration tests the paper reports significant common long-term trends between REITs and bond returns over the full sample horizon, a result which does not hold for the post-1992 sub-period. In this respect papers such as Glascock et al. 
(2000), Swanson et al. (2002) and Cheong et al. (2009) all argue for structural shifts in the interest rate sensitivity of REITs at various points in time. Nonetheless, the two latter papers find that these shifts do not affect REIT's interest rate sensitivity in general and both document the economic significance of interest rates. It is however imperative that a distinction is made between papers such as Glascock et al. (2000) and Cheong et al. (2009) who analyse fixed income index data and studies such as Devaney (2001), He et al. (2003) and Stevenson et al. (2007) that based their analysis on either market interest rates or bond yields.

While the aforementioned studies provide valuable insights into the interest rate exposure of publically listed real estate, they also frequently provide conflicting results due to the inconsistent choice of interest rate proxy. Not only is the rationale behind the selection of a specific proxy often of an arbitrary nature, but previous studies suffer from the limitation that interest rate proxies cannot be simultaneously incorporated in a single model. Furthermore, interest rate changes of different maturities are not independent due to the policy transmission mechanism from short to long-term rates. Papers such as Swanson et al. (2002) and He et al. (2003) incorporate a term-spread variable into their analysis. Used as a proxy for changes in the term structure the variable is defined as the spread between long and short term interest rates. Whilst it does capture some elements of the yield curve, it does not necessarily reflect some important features of the term structure that can commonly occur. In particular, such a measure does not capture changes in the shape of the yield curve (e.g. S-type or humped shape) and other non-parallel shifts. Diebold et al. (2005) argue that information concerning bond pricing is concentrated in a small number of systematic risk factors, which itself implies a high correlation between interest rates of different maturities ${ }^{\mathrm{iii}}$. A possible solution to the interest rate risk proxy choice is found in the yield curve literature. In particular, Nelson \& Siegel (1987) suggest an exponential components model where a large range of interest rates can be described through just 
three factors. In this paper, we use a dynamic version of Nelson-Siegel model, as proposed by Diebold and Li (2006):

$$
y_{t}(\tau)=\beta_{1 t}+\beta_{2 t}\left(\frac{1-e^{-\lambda_{t} \tau}}{\lambda_{t} \tau}\right)+\beta_{3 t}\left(\frac{1-e^{-\lambda_{t} \tau}}{\lambda_{t} \tau}-e^{-\lambda_{t} \tau}\right)
$$

where $y_{t}(\tau)$ is the yield of a zero-coupon bond, with time-to-maturity $\tau$ at $t . \beta_{1 t}, \beta_{2 t}$ , $\beta_{3 t}$ are the three parameters which represent the level, slope and curvature of the yield curve respectively. Finally, $\lambda$ represents the exponential decay rate. Based on the model parameterisation above, the loading on the level $\left(\beta_{1 t}\right)$ is equal to 1 and is independent of the time-to-maturity. Taking the limit, it is easy to see that $\lim _{t \rightarrow \infty} y_{t}(\tau)=\beta_{1 t}$ and hence the yield curve level can be seen as the long-term factor. A decrease in $\beta_{1 t}$ would affect all yields identically, thereby shifting the level of the yield curve. The loading on the slope parameter $\beta_{2 t}$ is driven by the exponential function, starting at 1 and decreasing monotonically to zero with increasing maturity. Therefore, the slope parameter may be seen as a short-term factor, and hence an increase in this factor would amplify short-rates more than long-term ones. In mathematical terms, given $\lim _{t \rightarrow 0} y_{t}(\tau)=\beta_{1 t}+\beta_{2 t}$, it is easy to see that $y_{t}(\infty)-y_{t}(0)=-\beta_{2 t}$. The loading on the last parameter $\beta_{3 t}$ (curvature) is also driven by the exponential function, which starts at zero (with maturity $\tau=0$ ), increases for the medium-term maturities, and then decays back to zero as maturity further increases. Accordingly, the yield curve curvature $\left(\beta_{3 t}\right)$ can be seen as the medium term factor. The Nelson-Siegel model fits the term structure using a flexible, smooth 
parametric function based on a Laguerre function. The model uses a small number of parameters and provides enough flexibility to capture a range of monotonic, S-type and humped shapes typically observed in yield curve data. Due to its ability to provide a good fit of the yield curve, the model is advocated by Diebold \& Li (2006), Fabozzi et al. (2005), and it is widely used by the Central Banks ${ }^{\text {iv }}$.

Since the value of any stock, including listed real estate firms, can be considered as equal to the present value of future cash-flows, a downward shift in the term structure of interest rates, as captured by our level factor, should lead to higher prices. We would also expect an inverse relationship between the slope, our proxy for short-term interest rates, and prices. Consistent with the ideas of Mishkin (1996) and Reinhart \& Simin (1997), short-term rates will be heavily influenced by Central Banks through inflation targets and the setting of prime/base rates. Existing empirical evidence that has documented an inverse relationship with rates of maturities ranging from 1 month to 20 years would support this premise (e.g. Chen \& Tzang, 1988; Devaney, 2001; Swanson et al., 2002; Stevenson et al., 2007). However, none of these studies consider a range of interest rates jointly. Therefore, using the factors we extract from the dynamic Nelson-Siegel model, we test the following hypothesis:

$H_{1}$ : There is an inverse relationship between real estate security returns and the changes in level, slope and curvature of the yield curve.

One of the key features that differentiates REITs from both property companies specifically and stocks generally is the minimum mandatory dividend payment that is required in most jurisdictions. As previously noted, this high yield nature would be expected to make REITs 
more sensitive to interest rates in the context of discounting future expected dividends (Bernanke \& Kuttner, 2005). Furthermore, high dividends and the coupon-like nature of the underlying rental income have been frequently identified as key reasons why REITs are felt to share some characteristics with fixed-income securities (e.g. Cheong et al., 2009). Given these issues we therefore anticipate a more pronounced reaction to changes in interest rates in markets where a REIT regime was in place throughout the sample period. Hence, we consider the following hypothesis:

$H_{2}$ : REIT shareholders should receive higher compensation for the interest rate risk exposure than both property specific and general stock market holders.

The results will allow us to consider which markets are more consistently exposed to interest rate risk. We also can examine whether countries with established REIT market are exposed to fluctuations in interest rates to a greater and more consistent degree.

\section{Data, model design and descriptive statistics}

\subsection{Interest Rate Data and Transformations}

As discussed in Section 2, one of the key objectives of the current paper is to examine the relationship between the yield curve and real estate securities. Diebold \& Li (2006) propose a variation of the Nelson \& Siegel (1987) parametric approach to modelling the yield curve. To estimate our interest rate risk factors (level, slope and curvature), we obtain from Bloomberg a series of estimated sovereign bond zero-coupon yields for twelve different maturities $(3,6,12$, $24,36,48,60,72,84,96,108,120$ months). Bloomberg derives the zero-coupon yields for the different maturities from observed bond prices by stripping the coupon bearing government notes 
and bonds using a bootstrapping approach ${ }^{\mathrm{v}}$. Descriptive statistics are reported in Table 1. Yields are then used as the initial estimates on the left-hand side of the Equation (1). Following Diebold \& Li (2006), Fabozzi et al. (2005) and Czaja et al. (2009), we obtain estimates for the level, slope and curvature as follows. The identified series of zero-coupon yields are regressed on the factor loadings and a constant using cross-sectional OLS (Ordinary Least Squares). With this model parameterisation the factor loadings on the right-hand side are calculated assuming a prefixed value of the decay parameter $\lambda$. Tam \& Yu (2008) and Bianchi et al. (2009) retain the same value of the parameter as suggested in Diebold \& Li (2006), namely 0.0609, reporting that the model satisfactorily fits the time-series for the countries they examine. A decay parameter of 0.0609 is equivalent to maximising the curvature, or medium-term factor, at 30 months. Yu \& Salyards (2009), however, illustrate using a sample of both investment-grade and speculativegrade bonds, that the optimal value of $\lambda$ can vary substantially for different set of bonds. Figure 1 demonstrates how the factor loadings in the model can be affected by the choice of $\lambda$.

\section{INSERT TABLE $1 \&$ FIGURE 1}

In light of this variation we evaluate the underlying model separately for each country, in line with the approach adopted by Yu \& Salyards (2009) ${ }^{\mathrm{vi}}$. Firstly, we estimate the model using different values of $\lambda$. Since the $\lambda$ parameter corresponds to the maturity at which the curvature, or medium-term factor, is maximised, we test the medium-term maturities within the range we have available. The model with the highest goodness-of-fit statistics is then selected. For Japan, Singapore, the U.K. and the U.S. the best fit is found with $\lambda=0.0374$, which is equivalent to the curvature factor being maximized at 48 months. For Hong Kong the $\lambda$ figure is 0.0747 , which 
corresponds to 24 months. Only in the case of Australia do we obtain a $\lambda$ parameter equal to that used in the Diebold \& Li (2006) paper. This not only supports the arguments of Yu \& Salyards (2009), but also justifies our decision to estimate $\lambda$ for each country individually ${ }^{\text {vii }}$.

In Figure 2, we plot the yield curve for randomly selected dates from the U.K. sample. The graph illustrates the ability of the model to fit different shapes of the yield curve. The best fit is found in the 'normal' shape yield curve, with the $R^{2}$ being 0.99 and the fitted line being almost indistinguishable from the original. A more modest fit is noticeable in humped, $S$-type and inverse yield curves. Overall we find that the Nelson-Siegel model explains on average $90 \%$ for each country in our sample, based upon the reported $R^{2}$ figures. However, whilst the $R^{2}$ does vary for the U.K. and U.S., it remains consistently very high throughout in the case of Japan. Figure 3 graphically displays the time-series of the three estimated parameters.

INSERT FIGURES $2 \& 3$

As suggested by Willner (1996) and Czaja et al. (2009) we convert the estimated factors into their first differenced form $\left(\Delta i r_{i, t}=i r_{i, t}-i r_{i, t-1}\right)$. Our study also extends previous contributions by considering the sensitivity of real estate equities to unexpected interest rate movements. Previous studies in the real estate literature have only considered actual interest rate changes. This is also true in the general finance literature, where only a small number of papers have based their empirical tests on unexpected interest rate changes ${ }^{\text {viii }}$.

The rationale behind the examination of unexpected changes is twofold. The first issue is based on the fact that if actual nominal changes in rates are examined the analysis effectively revolves around inflation expectations given that the volatility of real interest rates is relatively 
small (e.g. Fama, 1975; Nelson \& Schwert, 1977). This argument is reflected in previous studies where researchers have employed a myriad of different expectation generating processes to extract interest rate 'innovations' (e.g. Bae, 1990; Madura \& Zarruk, 1995). Secondly, studies in the mainstream literature such as Bernanke \& Kuttner (2005) have highlighted the importance of adjusting for expectations when considering interest rates and monetary shocks. These findings have also been supported in the context of both the U.S. REIT sector (Bredin et al., 2007, 2011) and global real estate markets (Xu \& Yang, 2011)

We estimate the unexpected changes in the yield curve factors using an Autoregressive Moving Average (ARMA) model. We model the unanticipated changes in the term structure factors as the difference between the actual changes in the respective factor at time $t$ and the ones forecasted via an appropriate $\operatorname{ARMA}(p, q)$ - model:

$$
\phi(L) i r_{i, t}=\theta(L) u_{i, t}
$$

where $i r_{i, t}=\left(\beta_{1 t}, \beta_{2 t}, \beta_{3 t}\right)^{\prime}$ is the set of Nelson-Siegel factors, $\phi(L)$ and $\theta(L)$ are the polynomial lag operators:

$$
\begin{aligned}
& \phi(L)=1-\phi_{1} L-\phi_{2} L^{2}-\ldots-\phi_{p} L^{p} \\
& \theta(L)=1+\theta_{1} L+\theta_{2} L^{2}+\ldots+\theta_{q} L^{q}
\end{aligned}
$$


hence, $u_{f, t}=(L, S, C)^{\prime}$ are the unexpected changes in level, slope and curvature of the yield curve. The use of only one expectation generating process is supported by the findings of Bae (1990) who, using three alternative models to form expectations, finds identical results regardless of the model employed ${ }^{\mathrm{ix}}$. The appropriate order of the autoregressive and moving average parameters used range from 0 to 5, depending on the variables and markets considered.

One further adjustment is made to the interest rate data. In order to assess the individual impact of each factor on returns we use an orthogonalisation procedure similar to that adopted by Czaja et al. (2009). It recognises the level factor $\left(L_{i, t}\right)$ for each country $i$ as the primary driver of yield curve changes, with the slope $\left(S_{i, t}\right)$ and curvature $\left(C_{i, t}\right)$ ranked second and third in importance respectively:

$$
\begin{aligned}
& S_{i, t}=\omega_{1}+\gamma_{1} L_{i, t}+\hat{s}_{i, t} \\
& C_{i, t}=\omega_{2}+\gamma_{2} L_{i, t}+\gamma_{3} \hat{s}_{i, t}+\hat{c}_{i, t}
\end{aligned}
$$

We therefore orthogonalise the slope factor with respect to the level, whilst also orthogonalising the curvature with respect to both yield curve level and slope. The orthogonalised series $\left(L_{i, t}, \hat{s}_{i, t}, \hat{c}_{i, t}\right)$ are then used as the exogenous variables in the empirical framework detailed in Section 3.3.

3.2 Public Real Estate, Stock Market and Other Control Variable Data 
Our analysis is based on six of the largest real estate equity markets in terms of market capitalisation and trading volume, namely; Australia, Hong Kong, Japan, Singapore, the U.K. and U.S. The sample data is weekly in frequency and covers the period January 1995 to December 2012. The real estate security indices used are collected from the FTSE EPRA/NAREIT database ${ }^{\mathrm{x}}$. Apart from the U.S. and Australia, the indices used are not solely comprised of REITs. This is especially so in the case of Hong Kong, where even after the introduction of REIT legislation in 2003 and the listing of the first trust in 2005 (The Link REIT), property companies remain the dominant vehicle. For the remaining countries REIT regulations came into being in 2000 (Japan), 2002 (Singapore) and 2007 (U.K.) respectively.

As well as the date at which REITs were introduced there are also differences across the six markets in terms of the amount of leverage REITs take on, as Figure 4 illustrates. In addition, the specific REIT regulations vary across the six markets. Whilst the majority do have some limit on the amount of debt a REIT can employ, there are no such restrictions in either Australia or the U.S. However, as can be seen from Figure 4, firms in those markets have lower leverage, on average, than in some countries with a set limit. In addition, the form of any restriction varies. Whilst U.K. firms are restricted on a cash flow basis by a minimum Debt Service Coverage Ratio of 1.25, in other markets limits are based on balance sheet data. For example, gearing is limited in Singapore to a maximum of $35 \%$ of total capital ${ }^{\mathrm{xi}}$.

Throughout the analysis we employ broad equity market indices as control variables. The indices used are the most common equity market benchmarks in each country, namely; ASX200 (Australia), Hang-Seng (Hong Kong), Nikkei 225 (Japan), Straits Times (Singapore), FTSE-100 (U.K.), and the S\&P500 (U.S.). The summary statistics for the securitised real estate and equity markets, together with the interest rate factors are reported in Table 2. Real estate stocks delivered a better performance over the period of study, while exhibiting higher volatility. A lack 
of normality is a common feature in financial time-series and we observe it for almost every variable of interest. In particular, most variables exhibit statistically significant skewness and excess kurtosis, resulting in a formal rejection of the Jarque-Bera normality test.

\section{INSERT FIGURE 4 \& TABLE 2}

\subsection{Model Design}

The methodological design we adopt in this paper is loosely based upon the GARCH specification first adopted in the context of interest rate sensitivity by Elyasiani \& Mansur (1998) and subsequently used in REIT/real estate security specific papers such as Devaney (2001), and Stevenson et al. (2007). Let $r_{i, t}$ denote the return on the public real estate index of country $i$. The GARCH(1,1) model can be described as follows:

$$
\begin{aligned}
& r_{i, t}=\mu_{0, i}+\beta_{1, i} \cdot L_{i, t}+\beta_{2, i} \cdot \hat{s}_{i, t}+\beta_{3, i} \cdot \hat{c}_{i, t}+\beta_{4, i} \cdot r_{i, t}^{M}+\varepsilon_{i, t} \\
& \varepsilon_{i, t}=z_{i, t} \cdot \sigma_{i, t} \\
& \sigma_{i, t}^{2}=a_{0, i}+a_{1, i} \cdot \varepsilon_{i, t}^{2}+b_{1, i} \cdot \sigma_{i, t-1}^{2}
\end{aligned}
$$

where $r_{i, t}^{M}$ is the domestic equity index returns, $L_{i, t}, \hat{s}_{i, t}, \hat{c}_{i, t}$ represent the set of unexpected Nelson-Siegel factors. $z_{i, t}$ is a sequence of independent, identically distributed

random variables with zero mean and unit variance, implying $\varepsilon_{i, t} \mid \boldsymbol{\Phi}_{i, t-1} \sim N\left(0, \sigma_{i, t}^{2}\right)$ is a 
conditionally normal heteroscedastic error term. $\boldsymbol{\Phi}_{i, t-1}$ is the information set available at time $t-1 . \beta_{1, i}, \beta_{2, i}, \beta_{3, i}$ represent the exposure of the real estate sector to interest rate risk. The coefficients are estimated using a quasi-maximum likelihood procedure with the normal likelihood function and robust standard errors as suggested by Bollerslev \& Wooldridge (1992).

The general GARCH framework also allows us to examine the impact of exogenous variables on the total risk of real estate securities, as measured by the conditional variance. We therefore extend the model (7)-(9) using two alternative conditional volatility specifications with respect to interest rate variables. The first specification uses unexpected changes in interest rates (Glosten et al., 1993). The second uses the conditional volatility of the interest rate series (Elyasiani \& Mansur, 1998; Stevenson et al., 2007):

$$
\begin{aligned}
& \sigma_{i, t}^{2}=a_{0, i}+a_{1, i} \cdot \varepsilon_{i, t}^{2}+b_{1, i} \cdot \sigma_{i, t-1}^{2}+g_{1, i} \cdot L_{i, t-1}+g_{2, i} \cdot \hat{s}_{i, t-1}+g_{3, i} \cdot \hat{c}_{i, t-1} \\
& \sigma_{i, t}^{2}=a_{0, i}+a_{1, i} \cdot \varepsilon_{i, t}^{2}+b_{1, i} \cdot \sigma_{i, t-1}^{2}+\tilde{g}_{1, i} \cdot h_{i, t-1}^{\text {level }}+\tilde{g}_{2, i} \cdot h_{i, t-1}^{\text {slope }}+\tilde{g}_{3, i} \cdot h_{i, t-1}^{\text {curv }}
\end{aligned}
$$

Overall, the model offers the opportunity to examine a number of hypotheses regarding listed real estate returns and volatility behaviour. Firstly, Equation (7) includes three interest rate proxies, namely the level, slope and curvature. Using a simple Wald coefficient restriction test we examine whether real estate security returns are sensitive to all three yield curve factors jointly (i.e. $\beta_{1, i}=\beta_{2, i}=\beta_{3, i}=0$ ). Secondly, we can use the augmented variance specifications (Equations 10a, 10b) and test whether our interest rate proxies, or their conditional volatilities, have a significant joint effect on the volatility of the listed real estate market: $g_{1, t}=g_{2, t}=g_{3, t}=0$ and $\tilde{g}_{1, t}=\tilde{g}_{2, t}=\tilde{g}_{3, t}=0$ respectively. Finally, we examine whether our set 
of interest rate factors affect jointly the returns volatility of listed real estate: $\beta_{1, i}=\beta_{2, i}=\beta_{3, i}=g_{1, t}=g_{2, t}=g_{3, t}=0$ and $\beta_{1, i}=\beta_{2, i}=\beta_{3, i}=\tilde{g}_{1, t}=\tilde{g}_{2, t}=\tilde{g}_{3, t}=0$.

\section{Empirical Results}

\subsection{Listed Real Estate and Interest Rate Risk}

We initially estimate the four-factor GARCH model, as specified in Equations (7)-(9) for each market, with the results reported in Table 3 . In addition to the overall sample period being examined we also run the empirical tests using two equal sub-samples, the mid-point being yearend 2002. For the full period of study, we find that the level (the long-term interest rate proxy) significantly influences listed real estate in both Australia and Singapore, whilst the Hong Kong and U.S. sectors are significantly sensitive to the slope factor. In all cases the significant coefficients are of the anticipated (negative) sign. Our results are consistent with previous REIT papers (e.g. Allen et al., 2000; Devaney, 2001), that report significant exposure to both short and long-term interest rates. However, none of the analysed markets are significantly exposed to movements in the curvature factor, which is the medium-term interest rates proxy.

One finding that is of particular interest is that Japan exhibits positive sensitivity to the slope factor over both the entire sample period and in the first sub-sample, implying that Japanese real estate stocks increase (decrease) in value following an increase (decrease) in the short-term interest rate. Such findings may, at least in part, be related to the prolonged period of economic stagnation and near-zero interest rate policy adopted in Japan during the years we analyse. Therefore, an increase in interest rates may have acted as a positive signal to the market if it was associated with improved expectations regarding economic conditions. 


\section{INSERT TABLE 3}

Another finding that is quite noticeable is that the results across the two sub-samples differ quite substantially. Indeed, the Australian REIT market is the only one to be consistently affected by the changes in the yield curve level at a statistically significant level. Australia is also the only market to report joint significance of the three yield curve factors across the different sample periods. We however, find that the U.S. market is sensitive to all three factors in the second subsample. In contrast, the previously reported exposure of the Hong Kong market to the changes in the slope factor is driven by the former sub-period. Consistent with Devaney (2001) and Stevenson et al. (2007) we confirm the time-varying nature of the interest rate sensitivity reported. While most previous studies in the area looked at individual markets and a single interest rate proxy, we find that often interest rate sensitivity may occur in some markets (i.e. the U.S. and the U.K.) and disappear in the others (i.e. Singapore, Japan and Hong Kong). It should be noted that our methodological framework effectively considers the excess interest rate exposure of listed real estate, over above the general equity market. Therefore, the results do not unequivocally imply that the listed real estate sectors in Hong Kong, Japan, and Singapore display no exposure to interest rate movements in the latter sub-period. In addition, there are other potential reasons behind the findings reported. For instance, the lack of significance in Singapore may be possibly associated with the unique monetary policy setting in the country. During the 1980s the Monetary Authority of Singapore (MAS) changed their policy objective to controlling inflation through the management of the Singapore dollar against a basket of currencies known as the trade-weighted exchange rate index (TWI). The TWI is now the main instrument in conducting monetary policy in Singapore instead of the traditional short-term 
interest rate. Exceptions do occur and are primarily during periods when the authorities needed to ensure sufficient liquidity in the money markets.

Our findings are similar in many respects to those reported in previous studies. For example, the U.K. results support the findings of Stevenson et al. (2007), in observing a positive but insignificant relationship between property company returns and short-term interest rates and a significant inverse relationship with long-term rates. In the U.S. the impact of long-term interest rates was previously noted by Devaney (2001) for Equity REITs. Overall, our findings suggest that interest rates exposure should be modelled beyond a single interest rate factor, and the factors from the Nelson-Siegel yield curve model are good candidates for such task. Overall, the results are consistent with the general theoretical formulation of the relationship between stocks/REITs and interest rates. However, it would be hard to describe the results as homogeneous, which is not surprising given the structural and legal differences across the international markets considered.

To fully consider the impact of interest rates on the volatility of listed real estate securities we test the two augmented GARCH specifications detailed in Equations (10a) and (10b). These specifications augment the base model with firstly the one-period lagged unexpected changes in the level, slope and curvature factors and secondly their respective oneperiod lagged conditional volatilities ${ }^{\mathrm{xii}}$. The results are reported in Table 4 and it is evident that volatility is strongly and, in the main, negatively affected by changes in the yield curve factors in Australia, U.K. and U.S. This would suggest that unanticipated changes in the yield curve factors translate into lower volatility of real estate returns in the subsequent period. Effectively, there is less volatility clustering since the markets adjust their expectations more efficiently using information from the money markets. Contrary to the results from the mean equation (Table 3), the curvature factor is found to be consistently relevant in explaining volatility behaviour in the 
U.K. and the U.S. This may be due to the use of derivatives to hedge interest rate exposure. Horng \& Wei (1999) argue that interest rate hedging is the primary reason for REITs employ derivatives. This is in part due to the fact that REITs have no incentive to use derivatives for tax purposes. However, the evidence would appear to indicate that the use of derivatives for hedging purposes is in reality relatively limited.

\section{INSERT TABLE 4}

With the exception of Singapore, we observe that the impact on volatility shifts from short-term rates to long-term rates and vice versa. This implies that information about the yield curve factor changes is an important determinant of volatility. Moreover, the impact may be hard to capture using conventional 'single' maturity models as the relationship is time-varying. Therefore, we test whether our interest rate proxies, and their conditional volatilities, have a significant joint effect on the volatility of securitised real estate markets. Wald test results on the joint significance of the yield curve factors are significant. We also find that real estate firms in all six markets are affected directly by the factors' changes rather than their volatilities.

\subsection{Asymmetric Responses to changes in the Yield Curve}

Given that our initial findings do indicate a degree of time-variation we expand the analysis to consider whether there are possible asymmetries present in how real estate security returns respond to the yield curve factors. Based upon the analysis contained in papers such as Bernanke \& Kuttner (2005), Bredin et al. (2007) and Xu \& Yang (2011) we conduct two alternative tests, 
which consider whether the sensitivity observed is dependent on firstly the sign and secondly the size of the unexpected change in the yield curve factors.

For the first test, considering the sign of the unanticipated change, we construct two dummy variables for each yield curve factor as follows: variables $D_{i, t}^{L+}, D_{i, t}^{S+}, D_{i, t}^{C+}$ take the value of 1 if there is a positive change in the level, slope or curvature respectively and 0 otherwise; variables $D_{i, t}^{L-}, D_{i, t}^{S-}, D_{i, t}^{C-}$ take the value of 1 if there is a negative change in the respective yield curve factors and 0 otherwise. Therefore, we test the following specification ${ }^{\text {xiii }}$ :

$$
\begin{gathered}
R_{i, t}=\mu_{0, i}+\beta_{1, i}^{+} \cdot L_{i, t} \cdot D_{i, t}^{L+}+\beta_{1, i}^{-} \cdot L_{i, t} \cdot D_{i, t}^{L-}+\beta_{2, i}^{+} \cdot S_{i, t} \cdot D_{i, t}^{S+}+\beta_{2, i}^{-} \cdot S_{i, t} \cdot D_{i, t}^{S-}+ \\
+\beta_{3, i}^{+} \cdot C_{i, t} \cdot D_{i, t}^{C+}+\beta_{3, i}^{-} \cdot C_{i, t} \cdot D_{i, t}^{C-}+\psi \cdot r_{i, t}^{M}+\varepsilon_{i, t} \\
\sigma_{i, t}^{2}=a_{0, i}+a_{1, i} \cdot \varepsilon_{i, t-1}^{2}+b_{1, i} \cdot \sigma_{i, t-1}^{2}+g_{1, i}^{+} \cdot L_{i, t-1} \cdot D_{i, t-1}^{L+}+g_{1, i}^{-} \cdot L_{i, t-1} \cdot D_{i, t-1}^{L-}+ \\
\quad+g_{2, i}^{+} \cdot S_{i, t-1} \cdot D_{i, t-1}^{S+}+g_{2, i}^{-} \cdot S_{i, t-1} \cdot D_{i, t-1}^{S-}+g_{3, i}^{+} \cdot C_{i, t-1} \cdot D_{i, t-1}^{C+}+g_{3, i}^{-} \cdot C_{i, t-1} \cdot D_{i, t-1}^{C-}
\end{gathered}
$$

The estimation results from Equation (11) are reported in Table 5. Overall, the evidence with respect to asymmetry is strongest in Australia and the U.S., with evidence indicating a significant reaction to all three yield curve factors. We find that U.S. REITs and the Hong Kong sector both react negatively to unexpected increases in the slope of the yield curve, which is associated with short-term rates. We find that positive changes in the slope factor, which would imply a contractionary monetary policy, drive securitised real estate prices downwards. Therefore, our initial multifactor model result for U.S. REITs, as reported in Table 3, are likely to be driven by the flatter slope of the yield curve, while the steeper slope, as an indication of economic expansion, has little effect on REIT returns. In Australia and Japan we find the opposite effect for positive slope changes. Returns in Australia also react negatively to increases 
in the level, consistent with the initial results for Australia and the view that they are driven by unexpected increases in short and long-term rates rather than reductions.

\section{INSERT TABLE 5}

The second test considers whether the size of unexpected changes in the yield curve factors affects the interest rate sensitivity observed. Xu \& Yang (2011) provide some evidence in support of this view in their analysis of how U.S. monetary shocks can affect international listed real estate markets. To analyse this issue we sort absolute values of the changes in each yield curve factor in ascending order and assign two dummy variables, $D_{f, i, t}^{\text {big }}$ and $D_{f, i, t}^{\text {small }}$, for each factor $f . D_{f}^{b i g}$ takes the value of 1 if the yield curve factor change is greater than the median factor change in absolute terms and zero otherwise, $D_{f, i, t}^{\text {small }}=1-D_{f, i, t}^{\text {big }}$. As a result, our model takes the following form:

$$
\begin{aligned}
R_{i, t}= & \mu_{0, i}+\beta_{1, i}^{\text {big }} \cdot L_{i, t} \cdot D_{L, i, t}^{\text {big }}+\beta_{1, i}^{\text {small }} \cdot L_{i, t} \cdot D_{L, i, t}^{\text {small }}+\beta_{2, i}^{\text {big }} \cdot S_{i, t} \cdot D_{S, i, t}^{\text {big }}+ \\
& +\beta_{2, i}^{\text {small }} \cdot S_{i, t} \cdot D_{S, i, t}^{\text {small }}+\beta_{3, i}^{\text {big }} \cdot C_{i, t} \cdot D_{C, i, t}^{\text {big }}+\beta_{3, i}^{\text {small }} \cdot C_{i, t} \cdot D_{C, i, t}^{\text {small }}+\psi \cdot r_{i, t}^{M}+\varepsilon_{i, t} \\
\sigma_{i, t}^{2}= & a_{0, i}+a_{1, i} \cdot \varepsilon_{i, t-1}^{2}+b_{1, i} \cdot \sigma_{i, t-1}^{2}+ \\
& +g_{1, i}^{\text {big }} \cdot L_{i, t-1} \cdot D_{L, i, t-1}^{\text {big }}+g_{1, i}^{\text {small }} \cdot L_{i, t-1} \cdot D_{L, i, t-1}^{\text {small }}+ \\
& +g_{2, i}^{\text {big }} \cdot S_{i, t-1} \cdot D_{S, i, t-1}^{\text {big }}+g_{2, i}^{\text {small }} \cdot S_{i, t-1} \cdot D_{S, i, t-1}^{\text {small }}+ \\
& +g_{3, i}^{\text {big }} \cdot C_{i, t-1} \cdot D_{C, i, t-1}^{\text {big }}+g_{3, i}^{\text {small }} \cdot C_{i, t-1} \cdot D_{C, i, t-1}^{\text {small }}
\end{aligned}
$$


The results are reported in Table 6 and reveal an interesting difference between the response in returns and volatility. It can be seen that volatility is particular sensitive to small changes in the yield curve factors, with significant results reported for Australia (slope and curvature), U.K. (slope and curvature), Hong Kong (level), and Singapore (slope). In contrast, returns are primarily affected by the magnitude of the change in the yield curve factors. In particular, large unexpected changes in the level are inversely related to returns in Australia and Singapore. Furthermore, large unexpected changes in the slope affect Hong Kong, Singapore and the U.S. Our results are consistent with those reported by $\mathrm{Xu} \&$ Yang (2011) who find that international listed real estate markets returns are mostly exposed to large changes in monetary policy. When we considers the Wald tests, the estimates for the large unexpected changes in the level and the slope of the yield curve are significantly different from the respective coefficients related to the small changes. Finally, it is of interest that in contrast to the base linear model, reported in Table 3, we do in this instance report statistically significant interest rate exposure in the case of Singapore. The original specification has failed to detect any significant interest rate sensitivity.

\section{INSERT TABLE 6}

\subsection{Robustness Tests}

The final component of the empirical analysis consists of a variety of alternative specifications and tests in order to consider the robustness of the results reported thus far. In the first instance we introduce two additional control variables, namely global stock market returns and trading volume. The global equity market is proxied by the MSCI World index returns $\left(r_{i, t}^{W}\right)$ 
and is included in addition to the domestic equity market benchmarks used thus far. The trading volume data is collected from the Thomson Reuters Datastream. Consistent with previous studies, we find that trading volume has a substantial time trend. Therefore, in order to ensure that the data is stationary we follow previous studies such as Campbell et al. (1993) and Hutson et al. (2008) and de-trend the data as follows:

$$
\log \left(\text { Volume }_{i, t}\right)=a_{0, i}+a_{1, i} \cdot T I M E+a_{2, i} \cdot T I M E^{2}+u_{i, t}
$$

The de-trended non-negative volume series $\left(\right.$ vol $\left._{i, t}\right)$ is defined as the residuals $\left(u_{i, t}\right)$ minus the minimum value of $u_{i, t}$. We augment the mean equation of our baseline GARCH specification as follows:

$$
r_{i, t}=\mu_{0, i}+\beta_{1, i} \cdot L_{i, t}+\beta_{2, i} \cdot \hat{s}_{i, t}+\beta_{3, i} \cdot \hat{c}_{i, t}+\beta_{4, i} \cdot r_{i, t}^{M}+\beta_{5, i} \cdot r_{i, t}^{W}+\beta_{6, i} \cdot v o l_{i, t}+\varepsilon_{i, t}
$$

The results are presented in Table 7 and are broadly consistent with the initial findings that were reported in Table 3. The specification that includes the global market returns and volume reveals that changes in the level of the yield curve has a stronger impact on U.S. REITs. We also find no support for the weak significance of the yield curve factors in Japan. Previously they have been reported to have an unexpected positive sign. The lack of statistical significance in Japan is however, consistent with Yourougou (1990) who reports no significant sensitivity during periods of low interest-rates. 


\section{INSERT TABLE 7}

The second robustness tests considers and incorporates into the analysis the impact of two major events during the sample period; namely the 1997-98 Asian Financial Crisis (AFC) and the Global Financial Crisis (GFC) a decade later. We restrict the AFC period from July 1997 until the end of June 1998 in line with Gerlach et al. (2006) and Kho \& Stulz (2000). We follow the Global Financial Crisis (GFC) timeline from Longstaff (2010), who defines the period as being from August 2007 through to December 2008 when the U.S. government started authorising lending through the Troubled Asset Relief Program (TARP). In order to explicitly consider whether either of these events significantly alter our findings we re-specify the GARCH models to incorporate a dummy variable relating to the two crisis'. This adapted specification can be displayed as follows:

$$
\begin{aligned}
R_{i, t}=\mu_{0, i}+\beta_{1, i} \cdot L_{i, t}+\beta_{1, i}^{F C} \cdot L_{i, t} \cdot D_{i, t}^{F C} & +\beta_{2, i} \cdot S_{i, t}+\beta_{2, i}^{F C} \cdot S_{i, t} \cdot D_{i, t}^{F C}+ \\
& +\beta_{3, i} \cdot C_{i, t}+\beta_{3, i}^{F C} \cdot C_{i, t} \cdot D_{i, t}^{F C}+\psi \cdot r_{i, t}^{M}+\varepsilon_{i, t}
\end{aligned}
$$

where the error term using the information set $\boldsymbol{\Omega}$ for country $i$ available at time $t-1$ is

conditionally normal and heteroscedastic and expressed as $\varepsilon_{i, t}=z_{i, t} \cdot \sigma_{i, t}$ and $\varepsilon_{i, t} \mid \boldsymbol{\Omega}_{i, t-1} \sim N\left(0, \sigma_{i, t}^{2}\right) .\left\{z_{i, t}\right\}$ is a sequence of independent, identically distributed random variables with zero mean and unit variance. $\mathbf{X}_{i, t}$ is the vector of the control variables that include market index returns, world index returns and de-trended trading volume. Variables $L, S$, and $C$ 
are the unexpected changes in the yield curve level, slope and curvature, all calculated at time $t$ as the difference between the actual changes in the yield curve level/slope/curvature and the ones forecasted via the appropriate specification of the ARMA model. The Financial Crisis dummy, $D_{i, t}^{F C}$, takes the value of unity during Asian Financial Crisis of 1997-1998 and Global Financial Crisis of 2007-2008. The volatility equation for securitised real estate is interchangeably augmented in two alternative ways:

$$
\begin{aligned}
\sigma_{i, t}^{2}=a_{0, i}+a_{1, i} & \varepsilon_{i, t-1}^{2}+b_{1, i} \cdot \sigma_{i, t-1}^{2}+g_{1, i} \cdot L_{i, t-1}+g_{1, i}^{F C} \cdot L_{i, t-1} \cdot D_{i, t-1}^{F C}+ \\
& +g_{2, i} \cdot S_{i, t-1}+g_{2, i}^{F C} \cdot S_{i, t-1} \cdot D_{i, t-1}^{F C}+g_{3, i} \cdot C_{i, t-1}+g_{3, i}^{F C} \cdot C_{i, t-1} \cdot D_{i, t-1}^{F C} \\
\sigma_{i, t}^{2}=a_{0, i}+a_{1, i} \cdot & \varepsilon_{i, t-1}^{2}+b_{1, i} \cdot \sigma_{i, t-1}^{2}+g_{1, i} \cdot h_{i, t-1}^{L}+g_{1, i}^{F C} \cdot h_{i, t-1}^{L} \cdot D_{i, t-1}^{F C}+ \\
& +g_{2, i} \cdot h_{i, t-1}^{S}+g_{2, i}^{F C} \cdot h_{i, t-1}^{S} \cdot D_{i, t-1}^{F C}+g_{3, i} \cdot h_{i, t-1}^{C}+g_{3, i}^{F C} \cdot h_{i, t-1}^{C} \cdot D_{i, t-1}^{F C}
\end{aligned}
$$

The equality of the interest rate coefficients during the crises and non-crises periods are tested using Wald tests. The estimation results are reported in Table 8. The specifications (17)(18a,b) serve as a further check to the initial sensitivities reported in Tables 3 and 4 . The yield curve factors enter the equations alongside interaction dummies. The estimates of the factors for the non-crises periods in Table 8 are consistent with what we report for the full sample in Table 3. Interaction crises variables add little to the results from the previous sections as they appear to be largely insignificant in explaining real estate security return behaviour. The lack of significance of the interest rate factors during the crises periods is consistent with Lizieri \& Satchel (1997) and Lizieri et al. (1998) who reported no sensitivity in either the U.S. or U.K. to interest rate changes during the periods of high volatility. 
With respect to volatility, the results are largely consistent and mostly support the findings previously reported and discussed. In addition, we find that during the two crises, volatility in Japan and the U.S. are affected by changes in the long-term interest rate factor, whilst in Australia volatility is linked to interest rate volatility. Interestingly, changes in the yield curve level factor have a calming effect on the total risk of securitised real estate in these three countries. The findings on volatility are supported by the Wald test for asymmetry between crises and non-crises periods.

\section{INSERT TABLE 8}

\section{Concluding Comments}

Despite the evident channels through which interest rates can potentially impact upon the listed real estate sector, the majority of the existing literature has focused predominantly upon the U.S. REIT sector. This extends that literature by considering six of the largest listed real estate markets globally. The results also extend the literature by considering a range of interest rate factors that more completely capture the dynamics of the yield curve and by focusing on unanticipated interest rate sensitivity. Overall, the results reveal the significance of both short and long-term interest rates factors in explaining the returns of securitized real estate with results displaying a high degree of robustness. In line with theoretical expectations, the real estate markets in all six countries exhibit significant sensitivity at one time or another. However, we find do find that sensitivity does vary across markets and over time. It is however, hard to specifically note whether any observed variation in results can be attributed to the legal structure 
in place. Specifically, the results do not clearly indicate that markets with a REIT regime in place throughout the sample period display heightened sensitivity.

The results do provide important implications for investors' assessment of interest rate risk and sensitivity in public real estate markets, highlighting the importance of interest rates in such markets. Furthermore, in contrast to previous studies which have concentrated on a single interest rate factor, the empirical results also illustrate the importance of considering movements across the entire term structure of interest rates. One area that the paper does not consider is contagion effects in the yield-curve factors in the different markets. This is an aspect that does warrant attention in future research as it would be of considerable interest to explore crosscountry dynamics, possibly using the Diebold et al. (2008) framework and include a global yield curve factor in addition to the country-specific yield factors. 


\section{References}

Allen, M., Madura, J., \& Springer, T. (2000). REIT Characteristics and the Sensitivity of REIT Returns, Journal of Real Estate Finance and Economics, 21, 141-152.

Bae, S. (1990). Interest Rate Changes and Common Stock Returns of Financial Institutions: Revisited, Journal of Financial Research, 13, 71-79.

Bank of International Settlements (2005). Zero-coupon yield curves - technical documentation. BIS Papers, No.25.

Bernanke, B., \& Blinder, A. (1992). The Federal Funds Rate and the Channels of Monetary Policy, American Economic Review, 82, 901-921.

Bernanke, B., \& Gertler, M., (1995). Inside the Black Box: The Credit Channel of Monetary Policy Transmission, Journal of Economic Perspectives, 9, 27-48.

Bernanke, B., \& Kuttner, K. (2005). What Explains the Stock Market's Reaction to Federal Reserve Policy?, Journal of Finance, 60, 1221-1257.

Bianchi, F., Mumtaz, H., \& Surico, P. (2009). The Great Moderation of the Term Structure of UK Interest Rates, Journal of Monetary Economics, 56, 856-871.

Bollerslev, T., \& Wooldridge, J. (1992). Quasi-Maximum Likelihood Estimation and Inference in Dynamic Models with Time-Varying Covariances, Econometric Reviews, 11, 143-172.

Bredin, D., O'Reilly, G., \& Stevenson, S. (2007). Monetary Shocks and REIT Returns, Journal of Real Estate Finance and Economics, 35, 315-331.

Bredin, D., O'Reilly, G., \& Stevenson, S. (2011). Monetary Policy Transmission and Real Estate Investment Trusts, International Journal of Finance and Economics, 16, 92-102.

Campbell J.Y., Grossman S.J., \& Wang J. (1993). Trading Volume and Serial Correlation in Stock Returns, Quarterly Journal of Economics, 108, 905-939.

Chan, S., Erickson, J., \& Wang, K. (2003). Real Estate Investment Trusts: Structure, Performance, and Investment Opportunities, Oxford University Press: Cambridge MA.

Chance, D. M. \& Lane, W. R. (1980). A Re-Examination of Interest Rate Sensitivity in the Common Stocks of Financial Institutions, Journal of Financial Research, 3, 49-55.

Chen, K., \& Tzang, D. (1988). Interest-Rate Sensitivity of Real Estate Investment Trusts, Journal of Real Estate Research, 3, 13-22.

Cheong, C., Gerlach, R., Stevenson, S., Wilson, P., \& Zurbruegg, R. (2009). Equity and Fixed Income Markets as Drivers of Securitised Real Estate, Review of Financial Economics, 18, 103-111.

Czaja, M., Scholz, H., \& Wilkens, M. (2009). Interest Rate Risk of German Financial Institutions: The Impact of Level, Slope, and Curvature of the Term Structure, Review of Quantitative Finance and Accounting, 33, 1-26. 
Devaney, M. (2001). Time Varying Risk-Premia for Real Estate Investment Trusts: A GARCH-M Model, Quarterly Review of Economics and Finance, 41, 335-346.

Diebold, F., \& Li, C. (2006). Forecasting the Term Structure of Government Bond Yields, Journal of Econometrics, 130, 337-364.

Diebold, F., Li, C., \& Yue, V. Z. (2008). Global Yield Curve Dynamics and Interactions: A Dynamic Nelson-Siegel Approach, Journal of Econometrics, 146, 351-363.

Diebold, F., Piazzesi, M., \& Rudebusch, G. (2005). Modeling Bond Yields in Finance and Macroeconomics, American Economic Review, 95, 415-420.

Dinenis, E., \& Staikouras, S. (1998). Interest Rate Changes and Common Stock Returns of Financial Institutions: Evidence from the UK, European Journal of Finance, 4, 113-127.

DiPasquale, D., \& Wheaton, W. (1992). The Markets for Real Estate Assets and Space: A Conceptual Framework, Journal of the American Real Estate \& Urban Economics Association, 20, 181-198.

Elyasiani, E., \& Mansur, I. (1998). Sensitivity of the Bank Stock Returns Distribution to Changes in the Level and Volatility of Interest Rate: A GARCH-M Model, Journal of Banking \& Finance, 22, 535-563

Fabozzi, F., Martellini, L., \& Priaulet, P. (2005). Predictability in the Shape of the Term Structure of Interest Rates. Journal of Fixed Income, 15, 40-53.

Faff, R.W., \& Howard, P.F. (1999). Interest Rate Risk of Australian Financial Sector Companies in a Period of Regulatory Change, Pacific-Basin Finance Journal, 7, 83-101.

Fama, E. (1975). Short-Term Interest Rates as Predictors of Inflation, American Economic Review, 65, 269-282.

Fisher, J. (1992). Integrating Research on Markets for Space and Capital, Real Estate Economics, 20, 161-180.

Flannery, M.J., \& James, C.M. (1984). The Effect of Interest Rate Changes on the Common Stock Returns of Financial Institutions, Journal of Finance, 39, 1141-1153.

Gerlach, R., Wilson, P., \& Zurbruegg, R. (2006). Structural Breaks \& Diversification: The Impact of the 1997 Asian Financial Crisis on the Integration of Asia-Pacific Real Estate Markets, Journal of International Money and Finance, 25, 941-991.

Glascock, J., Lu, C., \& So, R. (2000). Further Evidence on the Integration of REIT, Bond, and Stock Returns, Journal of Real Estate Finance and Economics, 20, 177-194.

Glosten, L., Jagannathan, R., \& Runkle, D. (1993). On the Relation between the Expected Value and the Volatility of the Nominal Excess Return on Stocks, Journal of Finance, 48, 1779-1801.

He, L., Webb, J., \& Myer, F. (2003). Interest Rate Sensitivities of REIT Returns, International Real Estate Review, 6, 1-21.

Horng, Y., \& Wei, P. (1999). An Empirical Study of Derivatives use in the REIT Industry, Real Estate Economics, 27, 561-586. 
Hutson, E., Kearney, C., \& Lynch, M. (2008). Volume and Skewness in International Equity Markets, Journal of Banking \& Finance, 32, 1255-1268.

Jaffe, J. (1991). Taxes and the Capital Structure of Partnerships, REIT's, and Related Entities, Journal of Finance, 46, 401-407.

Kho, B.C., \& Stulz, R.M. (2000) Banks, the IMF and the Asian crisis, Pacific-Basin Finance Journal, 8 , $177-216$.

Koopman, S. J., Mallee, M. I., \& Van der Wel, M. (2010). Analyzing the Term Structure of Interest Rates using the Dynamic Nelson-Siegel Model with Time-Varying Parameters, Journal of Business \& Economic Statistics, 28, 329-343.

Liang, Y., McIntosh, W., \& Webb, J. (1995). Intertemporal Changes in the Riskiness of REITs, Journal of Real Estate Research, 10, 427-443.

Ling, D. \& Naranjo, A. (1997). Economic Risk Factors and Commercial Real Estate Returns, Journal of Real Estate Finance and Economics, 15, 283-308.

Liow, K., Ooi, J.T.L., \& Wang, L.K. (2003). Interest Rate Sensitivity and Risk Premium of Property Stocks, Journal of Property Research, 20, 117-132.

Litterman, R., \& Scheinkman, J. (1991). Common Factors affecting Bond Returns, Journal of Fixed Income, 1, 54-61.

Lizieri, C., \& Satchell, S. (1997). Property Company Performance and Real Interest Rates: A RegimeSwitching Approach, Journal of Property Research, 14, 85-97.

Lizieri, C., Satchell, S., Worzala, E., \& Dacco, R. (1998). Real Interest Regimes and Real Estate Performance: A Comparison of UK and US Markets, Journal of Real Estate Research, 16, 339-356.

Longstaff, F.A. (2010). The Subprime Credit Crisis and Contagion in Financial Markets, Journal of Financial Economics, 97(3), 436-450.

Madura, J., \& Zarruk, E. (1995). Bank Exposure to Interest Rate Risk: A Global Perspective, Journal of Financial Research, 18, 1-13.

Mishkin, F.S. (1996). The Channels of Monetary Transmission: Lessons for Monetary Policy, NBER working paper 5464, 1-27.

Nelson, C., \& Schwert, G. (1977). Short-Term Interest Rates as Predictors of Inflation: On Testing the Hypothesis that the Real Rate of Interest is Constant, American Economic Review, 67, 478-486.

Nelson, C., \& Siegel, A. (1987). Parsimonious Modeling of Yield Curves, Journal of Business, 60, 473489.

Ooi, J., Ong, S., \& Li, L. (2010). An Analysis of the Financing Decisions of REITs: The Role of Market Timing and Target Leverage, Journal of Real Estate Finance and Economics, 40, 130-160. 
Plazzi, A., Torous, W. \& Valkanov, R. (2008). The Cross-Sectional Dispersion of Commercial Real Estate Returns and Rent Growth: Time Variation and Economic Fluctuations, Real Estate Economics, 36, 403-439.

Psaltis, E., \& Chubb, S. (2008). Riding out the Storm, Ernst \& Young: Global Real Estate Investment Trusts Report.

Reinhart, V., \& Simin, T. (1997). The Market Reaction to Federal Reserve Policy Action from 1989 to 1992, Journal of Economics and Business, 49, 149-168.

Serrano, C., \& Hoesli, M. (2009). Global Securitized Real Estate Benchmarks and Performance, Journal of Real Estate Portfolio Management, 15, 1-19.

Stevenson, S., Wilson, P., \& Zurbruegg, R. (2007). Assessing the Time-Varying Interest Rate Sensitivity of Real Estate Securities, European Journal of Finance, 13, 705-715.

Swanson, Z., Theis, J., \& Casey, K. (2002). REIT Risk Premium Sensitivity and Interest Rates, Journal of Real Estate Finance and Economics, 24, 319-330.

Tam, C., \& Yu, I. (2008). Modelling Sovereign Bond Yield Curves of the US, Japan and Germany, International Journal of Finance and Economics, 13, 82-91.

Willner, R. (1996). A New Tool for Portfolio Managers, Journal of Fixed Income, 6, 48-59.

Xu, P., \& Yang, J. (2011). US Monetary Policy Surprises and International Securitized Real Estate Markets, Journal of Real Estate Finance and Economics, 43, 459-490.

Yourougou, P. (1990). Interest-Rate Risk and the Pricing of Depository Financial Intermediary Common Stock: Empirical Evidence, Journal of Banking \& Finance, 14, 803-820.

Yu, W.-C., \& Salyards, D. (2009). Parsimonious Modeling and Forecasting of Corporate Yield Curve, Journal of Forecasting, 28, 73-8 
Table 1: Descriptive statistics for the yield curves

\begin{tabular}{|c|c|c|c|c|c|c|c|c|c|}
\hline $\begin{array}{l}\text { Maturity } \\
\text { (Months)/Factor }\end{array}$ & Mean & Median & Max. & Min. & Std.Dev. & Skewness & Kurtosis & JB test & Obs. \\
\hline \multicolumn{10}{|l|}{ US } \\
\hline 3 & 3.006 & 3.297 & 6.460 & 0.002 & 2.221 & -0.09 & $1.36^{* * * *}$ & $105.96 * * *$ & 930 \\
\hline 36 & 3.751 & 4.053 & 8.024 & 0.284 & 2.041 & $-0.15^{*}$ & $1.76^{* * *}$ & $63.54 * * *$ & 930 \\
\hline 60 & 4.131 & 4.371 & 8.025 & 0.616 & 1.781 & $-0.22 * * *$ & $2.10^{* * *}$ & $38.41 * * *$ & 930 \\
\hline 120 & 4.745 & 4.706 & 8.125 & 1.539 & 1.357 & $-0.16^{* *}$ & $2.69 * * *$ & $7.56 * *$ & 930 \\
\hline Level & 5.843 & 5.955 & 8.202 & 3.220 & 0.930 & $-0.26^{* * * *}$ & $3.13^{* * * *}$ & $11.18 * * *$ & 930 \\
\hline Slope & -2.819 & -2.305 & 0.755 & -6.384 & 2.078 & -0.11 & $1.62 * * *$ & $75.68 * * *$ & 930 \\
\hline Curvature & -1.895 & -1.646 & 3.612 & -8.142 & 2.201 & $-0.31^{* * * *}$ & $2.46^{* * * *}$ & $25.64 * * *$ & 930 \\
\hline \multicolumn{10}{|l|}{ Australia } \\
\hline 3 & 5.252 & 5.037 & 8.780 & 2.450 & 1.239 & $0.25 * * *$ & $2.91 * * *$ & $9.60 * * *$ & 926 \\
\hline 12 & 5.328 & 5.152 & 10.095 & 2.516 & 1.309 & $0.48 * * *$ & $3.71 * * *$ & $54.69 * * *$ & 926 \\
\hline 36 & 5.586 & 5.417 & 10.708 & 2.277 & 1.367 & $0.51 * * *$ & $4.49 * * *$ & $124.71 * * *$ & 926 \\
\hline 60 & 5.782 & 5.616 & 10.673 & 2.353 & 1.378 & $0.64 * * *$ & $4.68 * * *$ & $171.75 * * *$ & 926 \\
\hline 120 & 6.062 & 5.812 & 10.751 & 2.800 & 1.374 & $1.00 * * *$ & $4.84 * * *$ & $283.43 * * *$ & 926 \\
\hline Slope & -1.059 & -0.946 & 0.933 & -3.846 & 1.077 & $-0.19^{* *}$ & $2.10 * * *$ & $36.65 * * *$ & 926 \\
\hline Curvature & -0.848 & -0.709 & 3.731 & -5.671 & 1.344 & $-0.46^{* * * *}$ & $3.81 * * *$ & $58.29 * * *$ & 926 \\
\hline \multicolumn{10}{|l|}{ UK } \\
\hline 3 & 4.157 & 4.800 & 7.550 & 0.144 & 2.203 & $-0.67 * * *$ & $2.17 * * *$ & $97.28 * * *$ & 932 \\
\hline 12 & 4.256 & 4.743 & 7.515 & 0.113 & 2.223 & $-0.63 * * *$ & $2.15 * * *$ & $89.89 * * *$ & 932 \\
\hline 36 & 4.560 & 4.825 & 8.784 & 0.133 & 2.048 & $-0.47 * * *$ & $2.48 * * *$ & $43.96^{* * * *}$ & 932 \\
\hline 60 & 4.732 & 4.830 & 8.999 & 0.543 & 1.858 & $-0.22 * * *$ & $2.75^{* * *} *$ & $9.85 * * *$ & 932 \\
\hline 120 & 5.005 & 4.780 & 8.967 & 1.559 & 1.573 & $0.60 * * *$ & $3.47 * * *$ & $64.38 * * *$ & 932 \\
\hline Level & 5.245 & 4.753 & 9.232 & 3.297 & 1.449 & $1.52 * * *$ & $4.20 * * *$ & $414.52 * * *$ & 932 \\
\hline Slope & -1.174 & -0.767 & 2.643 & -5.822 & 2.300 & $-0.42 * * *$ & $1.98 * * *$ & $67.65 * * *$ & 932 \\
\hline Curvature & -0.073 & 0.182 & 7.731 & -7.028 & 2.887 & $-0.21 * * *$ & $3.31 * * *$ & $10.80^{* * * *}$ & 932 \\
\hline \multicolumn{10}{|l|}{ Hong Kong } \\
\hline 3 & 2.939 & 2.855 & 10.930 & 0.004 & 2.598 & $0.52 * * *$ & 2.35 *** & $55.85 * * *$ & 896 \\
\hline 12 & 3.255 & 2.970 & 10.831 & 0.114 & 2.659 & $0.49 * * *$ & $2.28 * * *$ & $54.62 * * *$ & 896 \\
\hline 36 & 3.940 & 3.876 & 10.781 & 0.131 & 2.559 & $0.33 * * *$ & $2.12 * * *$ & $44.63 * * *$ & 896 \\
\hline 60 & 4.434 & 4.110 & 10.702 & 0.237 & 2.452 & $0.20 * *$ & $2.06^{* * *}$ & $38.99 * * *$ & 896 \\
\hline Slope & -2.496 & -2.452 & 4.006 & -6.547 & 1.496 & $-0.18 * *$ & $3.22 * * *$ & $6.76^{* *}$ & 896 \\
\hline Curvature & -1.627 & -1.321 & 6.113 & -6.035 & 2.034 & 0.02 & $2.99 * * *$ & 0.04 & 896 \\
\hline \multicolumn{10}{|l|}{ Japan } \\
\hline 3 & 0.263 & 0.132 & 2.245 & 0.002 & 0.335 & $3.06^{* * *}$ & $16.37^{* * *} *$ & $8,121.4^{* * *}$ & 902 \\
\hline 12 & 0.320 & 0.176 & 2.490 & 0.006 & 0.366 & $2.71 * * *$ & $14.20 * * *$ & $5,821.9 * * *$ & 902 \\
\hline 36 & 0.598 & 0.472 & 3.492 & 0.075 & 0.515 & $2.25 * * *$ & $10.95 * * *$ & $3,138.7 * * *$ & 902 \\
\hline 60 & 0.955 & 0.829 & 4.161 & 0.170 & 0.645 & $1.79 * * *$ & $7.75 * * *$ & $1,329.5 * * *$ & 902 \\
\hline 120 & 1.716 & 1.518 & 4.858 & 0.459 & 0.739 & $1.61 * * *$ & $5.92 * * *$ & 710.83 *** & 902 \\
\hline Level & 3.008 & 2.831 & 5.664 & 1.093 & 0.747 & $1.05^{* * *}$ & $4.58 * * *$ & $259.32 * * *$ & 902 \\
\hline Slope & -2.677 & -2.591 & -0.984 & -4.684 & 0.711 & $-0.79 * * *$ & $3.46^{* * *}$ & $101.47 * * *$ & 902 \\
\hline Curvature & -3.349 & -3.504 & 0.407 & -5.266 & 1.094 & $0.58 * * *$ & $2.62 * * *$ & $55.57 * * *$ & 902 \\
\hline \multicolumn{10}{|l|}{ Singapore } \\
\hline 3 & 1.347 & 1.104 & 4.142 & 0.008 & 0.923 & $0.55 * * *$ & $2.22 * * *$ & $69.03 * * *$ & 914 \\
\hline 12 & 1.488 & 1.373 & 4.142 & 0.089 & 0.908 & $0.33 * * *$ & $2.03 * * *$ & $52.86 * * *$ & 914 \\
\hline 36 & 2.019 & 2.078 & 7.036 & 0.270 & 1.005 & 0.02 & $2.60 * * *$ & $6.20^{* * *}$ & 914 \\
\hline 60 & 2.558 & 2.655 & 5.239 & 0.443 & 1.064 & $-0.26^{* * * *}$ & $2.21 * * *$ & $33.54 * * *$ & 914 \\
\hline 120 & 3.256 & 3.215 & 5.885 & 1.343 & 0.888 & 0.09 & $2.57 * * *$ & $8.41^{* *}$ & 914 \\
\hline Level & 4.051 & 3.993 & 6.262 & 0.730 & 0.738 & 0.05 & $2.87 * * *$ & 0.97 & 914 \\
\hline Slope & -2.880 & -2.894 & 1.296 & -5.490 & 1.198 & $0.24 * * *$ & $2.41 * * *$ & $21.57 * * *$ & 914 \\
\hline Curvature & -1.182 & -1.185 & 13.819 & -6.020 & 2.560 & $0.25^{* * * *}$ & $3.34 * * *$ & $13.76^{* * * *}$ & 914 \\
\hline
\end{tabular}

The table presents descriptive statistics for countries' yields at representative maturities, and each country's yield curve level, slope, and curvature estimated using the following equation:

$y_{t}(\tau)=\beta_{1 t}+\beta_{2 t}\left(\frac{1-e^{-\lambda_{t} \tau}}{\lambda_{t} \tau}\right)+\beta_{3 t}\left(\frac{1-e^{-\lambda_{t} \tau}}{\lambda_{t} \tau}-e^{-\lambda_{t} \tau}\right)$

where $y_{t}(\tau)$ is the yield on a zero-coupon bond, with time-to-maturity $\tau . \beta_{1 t}, \beta_{2 t}, \beta_{3 t}$ are the three estimated parameters which represent the level, slope and curvature of each country's yield curve respectively, and $\lambda$ represents the exponential decay rate. We use weekly data over the sample period of 1995-2012 
Table 2: Descriptive Statistics for securitised real estate, stock markets and the yield curve factors.

\begin{tabular}{|c|c|c|c|c|c|c|c|c|c|c|c|c|c|c|}
\hline & Mean & Median & Std. Dev. & Min. & Max. & Skew. & Kurt. & $\mathrm{JB}$ & Obs. & & Market & Level & Slope & Curvature \\
\hline & $U S$ & & & & & & & & & & & & & \\
\hline Real Estate & 0.110 & 0.250 & 21.793 & -24.475 & 3.333 & $-0.79 * * *$ & $13.08 * * *$ & $4,018.47 * * *$ & 927 & Real Estate & $0.69 * * *$ & $0.07 * *$ & -0.04 & $0.07 * *$ \\
\hline Stock Market & 0.123 & 0.341 & 10.344 & -16.748 & 2.480 & $-0.70 * * *$ & $7.50 * * *$ & $856.69 * * *$ & 927 & Market & 1 & $0.13^{* * *}$ & 0.00 & $0.10^{* * *}$ \\
\hline Level & 0.000 & -0.001 & 0.657 & -0.641 & 0.136 & -0.12 & $5.34 * * *$ & $214.38 * * *$ & 928 & Level & & 1 & $-0.76 * * *$ & -0.03 \\
\hline Slope & 0.000 & 0.008 & 0.660 & -1.448 & 0.172 & $-1.08 * * *$ & $11.25 * * *$ & $2,812.38 * * *$ & 927 & Slope & & & 1 & $-0.12 * * *$ \\
\hline \multirow[t]{2}{*}{ Curvature } & 0.002 & -0.025 & 1.550 & -2.126 & 0.405 & 0.08 & $4.64 * * *$ & $104.66^{* * *}$ & 928 & Curvature & & & & 1 \\
\hline & \multicolumn{2}{|c|}{ Australia } & & & & & & & & & & & & \\
\hline Real Estate & 0.024 & 0.109 & 16.981 & -24.147 & 2.643 & $-0.50 * * *$ & $17.96 * * *$ & $8,609.48 * * *$ & 919 & Real Estate & $0.64 * * *$ & -0.03 & 0.04 & 0.04 \\
\hline Stock Market & 0.096 & 0.181 & 11.604 & -11.988 & 2.140 & $-0.51 * * *$ & $6.11^{* * *}$ & $409.13 * * *$ & 919 & Market & 1 & $0.09 * * *$ & -0.01 & $0.13^{* * *}$ \\
\hline Level & -0.001 & -0.003 & 0.666 & -0.613 & 0.151 & $0.18^{* *}$ & $3.87 * * *$ & $34.24 * * *$ & 919 & Level & & 1 & $-0.60 * * *$ & $0.08 * *$ \\
\hline Slope & 0.001 & 0.007 & 1.230 & -1.716 & 0.202 & $-0.87 * * *$ & $12.47 * * *$ & $3,551.94 * * *$ & 919 & Slope & & & 1 & $-0.31 * * *$ \\
\hline Curvature & $\begin{array}{r}0.003 \\
U K \\
\end{array}$ & 0.006 & 2.037 & -2.014 & 0.357 & 0.03 & $8.12 * * *$ & $1,004.82 * * *$ & 919 & Curvature & & & & 1 \\
\hline Real Estate & 0.032 & 0.282 & 15.994 & -18.608 & 3.123 & $-0.55 * * *$ & $9.13^{* * * *}$ & $1,503.57 * * *$ & 930 & Real Estate & $0.57^{* * * *}$ & 0.05 & -0.03 & 0.11 *** \\
\hline Stock Market & 0.069 & 0.285 & 13.344 & -12.437 & 2.415 & $-0.37 * * *$ & $6.43 * * *$ & $478.12 * * *$ & 930 & Market & 1 & $0.08 * *$ & 0.01 & $0.11 * * *$ \\
\hline Level & 0.000 & 0.003 & 0.802 & -0.940 & 0.121 & $-0.52 * * *$ & $11.36 * * *$ & $2,755.43 * * *$ & 931 & Level & & 1 & $-0.70 * * *$ & $-0.22 * * *$ \\
\hline Slope & 0.000 & -0.003 & 1.203 & -0.854 & 0.158 & 0.05 & $9.79 * * *$ & $1,788.71^{* * * *}$ & 931 & Slope & & & 1 & -0.04 \\
\hline \multirow[t]{2}{*}{ Curvature } & -0.004 & -0.019 & 2.123 & -1.389 & 0.413 & $0.49^{* * *}$ & $5.17 * * *$ & $219.99 * * *$ & 931 & Curvature & & & & 1 \\
\hline & \multicolumn{2}{|c|}{ Hong Kong } & & & & & & & & & & & & \\
\hline Real Estate & 0.143 & 0.255 & 21.494 & -25.435 & 4.466 & $-0.20 * *$ & $6.20^{* * *}$ & $386.45^{* * * *}$ & 890 & Real Estate & $0.93 * * *$ & $-0.07 * *$ & $-0.23 * * *$ & $0.07 * *$ \\
\hline Stock Market & 0.103 & 0.142 & 13.524 & -20.912 & 3.457 & $-0.54 * * *$ & $6.36^{* * *}$ & $461.81 * * *$ & 890 & Market & 1 & $-0.06^{*}$ & $-0.22 * * *$ & $0.07 * *$ \\
\hline Level & 0.000 & -0.005 & 1.125 & -0.634 & 0.184 & $0.49 * * *$ & $6.67 * * *$ & $536.01 * * *$ & 891 & Level & & 1 & $-0.27 * * *$ & $-0.10^{* * * *}$ \\
\hline Slope & 0.000 & 0.004 & 3.653 & -2.844 & 0.365 & $0.38^{* * *}$ & $25.32 * * *$ & $18,509.66^{* * * *}$ & 891 & Slope & & & 1 & $-0.47 * * *$ \\
\hline Curvature & $\begin{array}{c}0.002 \\
\quad \text { Japan }\end{array}$ & -0.008 & 4.931 & -3.004 & 0.519 & $0.73 * * *$ & $18.26 * * *$ & $8,727.08 * * *$ & 891 & Curvature & & & & 1 \\
\hline Real Estate & 0.055 & 0.063 & 20.197 & $\begin{array}{l}-21.503 \\
\end{array}$ & 4.803 & 0.00 & $5.07 * * *$ & $160.15^{* * * *}$ & 900 & Real Estate & $0.75^{* * * *}$ & $0.10^{\text {**** }}$ & $-0.12 * * *$ & $0.10^{* * * *}$ \\
\hline Stock Market & -0.062 & 0.076 & 15.542 & -20.482 & 3.004 & $-0.31 * * *$ & $6.55^{* * *}$ & $487.53 * * *$ & 900 & Market & 1 & $0.15^{* * *}$ & $-0.20 * * *$ & $0.12 * * *$ \\
\hline Level & -0.001 & -0.004 & 0.820 & -0.752 & 0.129 & $0.70 * * *$ & 12.50 *** & $3,460.68^{* * *}$ & 901 & Level & & 1 & $-0.92 * * *$ & $-0.54 * * *$ \\
\hline Slope & 0.000 & 0.008 & 0.593 & -0.899 & 0.127 & $-1.00 * * *$ & $10.90 * * *$ & $2,496.29 * * *$ & 901 & Slope & & & 1 & $0.38 * * *$ \\
\hline \multirow[t]{2}{*}{ Curvature } & 0.000 & 0.007 & 1.583 & -1.848 & 0.296 & $-0.20 * *$ & $9.60 * * *$ & $1,637.47 * * *$ & 900 & Curvature & & & & 1 \\
\hline & \multicolumn{2}{|c|}{ Singapore } & & & & & & & & & & & & \\
\hline Real Estate & -0.005 & 0.201 & 24.671 & -29.259 & 4.783 & -0.08 & $7.27 * * *$ & $693.22 * * *$ & 911 & REIT & $0.82 * * *$ & 0.00 & $-0.10 * * *$ & $0.06^{*}$ \\
\hline Stock Market & 0.036 & 0.164 & 17.597 & -19.769 & 3.136 & $-0.18 * *$ & $6.88 * * *$ & $576.51 * * *$ & 911 & Market & 1 & 0.04 & $-0.09 * * *$ & $0.06^{*}$ \\
\hline Level & 0.000 & -0.002 & 2.912 & -2.749 & 0.239 & $-0.42 * * *$ & $64.25 * * *$ & $142,431.60 * * *$ & 911 & Level & & 1 & $-0.52 * * *$ & $-0.63 * * *$ \\
\hline Slope & 0.001 & 0.012 & 2.134 & -3.576 & 0.294 & $-1.21 * * *$ & $33.62 * * *$ & $35,762.52 * * *$ & 910 & Slope & & & 1 & -0.02 \\
\hline Curvature & 0.000 & -0.018 & 12.310 & -4.416 & 0.692 & $6.03 * * *$ & $116.32 * * *$ & $492,981.40 * * *$ & 911 & Curvature & & & & 1 \\
\hline
\end{tabular}

also reported for the level, slope and curvature yield curve factors. $*, * *, * * *$ indicate significance at the $10 \%, 5 \%$ and $1 \%$ levels, respectively. 
Table 3: GARCH Multifactor model results

\begin{tabular}{|c|c|c|c|c|c|c|c|c|c|}
\hline Period & $\mu_{0, i}$ & $\beta_{1, i}$ & $\beta_{2, i}$ & $\beta_{3, i}$ & $\beta_{4, i}$ & $a_{1, i}$ & $b_{1, i}$ & $\operatorname{Adj} \cdot R^{2}$ & Wald \\
\hline \multicolumn{10}{|l|}{$U S$} \\
\hline $1995-2012$ & $\begin{array}{l}0.066 \\
(0.07)\end{array}$ & $\begin{array}{l}-1.498 \\
(1.03)\end{array}$ & $\begin{array}{l}-1.813^{*} \\
(1.02)\end{array}$ & $\begin{array}{l}-0.157 \\
(0.16)\end{array}$ & $\begin{array}{l}0.643 \text { *** } \\
(0.03)\end{array}$ & $\begin{array}{l}0.118^{* * * *} \\
(0.03)\end{array}$ & $\begin{array}{l}0.873 * * * \\
(0.02)\end{array}$ & 0.43 & $\begin{array}{l}3.33 \\
(0.34)\end{array}$ \\
\hline $1995-2003$ & $\begin{array}{l}0.171 * * * \\
(0.06)\end{array}$ & $\begin{array}{l}-1.325 \\
(1.12)\end{array}$ & $\begin{array}{l}-0.660 \\
(1.21)\end{array}$ & $\begin{array}{l}-0.003 \\
(0.16)\end{array}$ & $\begin{array}{l}0.409 * * * \\
(0.03)\end{array}$ & $\begin{array}{l}0.227 * * * \\
(0.06)\end{array}$ & $\begin{array}{l}0.759 * * * \\
(0.05)\end{array}$ & 0.30 & $\begin{array}{l}2.05 \\
(0.56)\end{array}$ \\
\hline 2004-2012 & $\begin{array}{l}0.105 \\
(0.10)\end{array}$ & $\begin{array}{l}-6.808^{* * *} * \\
(1.59)\end{array}$ & $\begin{array}{l}-3.636^{* * * *} \\
(1.40)\end{array}$ & $\begin{array}{l}-0.875^{* * *} \\
(0.29)\end{array}$ & $\begin{array}{l}1.249^{* * * *} \\
(0.05)\end{array}$ & $\begin{array}{l}0.096^{* * *} \\
(0.04)\end{array}$ & $\begin{array}{l}0.883^{* * * *} \\
(0.04)\end{array}$ & 0.65 & $\begin{array}{l}25.71 * * * \\
(0.00)\end{array}$ \\
\hline \multicolumn{10}{|l|}{ Australia } \\
\hline $1995-2012$ & $\begin{array}{l}0.072 \\
(0.05)\end{array}$ & $\begin{array}{l}-1.277 \text { *** } \\
(0.31)\end{array}$ & $\begin{array}{l}0.298 \\
(0.41)\end{array}$ & $\begin{array}{l}-0.248 \\
(0.15)\end{array}$ & $\begin{array}{l}0.618 \text { *** } \\
(0.03)\end{array}$ & $\begin{array}{l}0.126^{* * * *} \\
(0.03)\end{array}$ & $\begin{array}{l}0.848 * * * \\
(0.04)\end{array}$ & 0.39 & $\begin{array}{l}23.90 * * * \\
(0.00)\end{array}$ \\
\hline $1995-2003$ & $\begin{array}{l}0.085 \\
(0.06)\end{array}$ & $\begin{array}{l}-1.398^{* * *} \\
(0.36)\end{array}$ & $\begin{array}{l}0.027 \\
(0.51)\end{array}$ & $\begin{array}{l}-0.324 * \\
(0.18)\end{array}$ & $\begin{array}{l}0.510^{* * * *} \\
(0.03)\end{array}$ & $\begin{array}{l}0.153^{* * * *} \\
(0.06)\end{array}$ & $\begin{array}{l}0.712^{* * * *} \\
(0.10)\end{array}$ & 0.37 & $\begin{array}{l}25.62 * * * \\
(0.00)\end{array}$ \\
\hline 2004-2012 & $\begin{array}{l}-0.015 \\
(0.07)\end{array}$ & $\begin{array}{l}-2.077 * * * \\
(0.65)\end{array}$ & $\begin{array}{l}0.486 \\
(0.57) \\
\end{array}$ & $\begin{array}{l}-0.365 \\
(0.33) \\
\end{array}$ & $\begin{array}{l}0.819 \text { *** } \\
(0.05)\end{array}$ & $\begin{array}{l}0.117 \text { *** } \\
(0.04)\end{array}$ & $\begin{array}{l}0.871 * * * \\
(0.04)\end{array}$ & 0.45 & $\begin{array}{l}12.86^{* * * *} \\
(0.00)\end{array}$ \\
\hline \multicolumn{10}{|l|}{ UK } \\
\hline $1995-2012$ & $\begin{array}{l}0.138 * * \\
(0.06)\end{array}$ & $\begin{array}{l}-0.193 \\
(0.59)\end{array}$ & $\begin{array}{l}-0.621 \\
(0.73)\end{array}$ & $\begin{array}{l}0.119 \\
(0.20)\end{array}$ & $\begin{array}{l}0.569 * * * \\
(0.04)\end{array}$ & $\begin{array}{l}0.136^{* * * *} \\
(0.03)\end{array}$ & $\begin{array}{l}0.828 * * * \\
(0.03)\end{array}$ & 0.31 & $\begin{array}{l}1.35 \\
(0.72)\end{array}$ \\
\hline $1995-2003$ & $\begin{array}{l}0.074 \\
(0.08)\end{array}$ & $\begin{array}{l}-0.277 \\
(0.71)\end{array}$ & $\begin{array}{l}-0.547 \\
(1.02)\end{array}$ & $\begin{array}{l}0.106 \\
(0.23)\end{array}$ & $\begin{array}{l}0.391 \text { *** } \\
(0.05)\end{array}$ & $\begin{array}{l}0.063^{* *} \\
(0.03)\end{array}$ & $\begin{array}{l}0.849 * * * \\
(0.09)\end{array}$ & 0.19 & $\begin{array}{l}0.76 \\
(0.86)\end{array}$ \\
\hline 2004-2012 & $\begin{array}{l}0.135 \\
(0.09) \\
\end{array}$ & $\begin{array}{l}-1.775^{*} \\
(1.02)\end{array}$ & $\begin{array}{l}0.423 \\
(1.08) \\
\end{array}$ & $\begin{array}{l}-0.236 \\
(0.32)\end{array}$ & $\begin{array}{l}0.996^{* * * *} \\
(0.05)\end{array}$ & $\begin{array}{l}0.148^{* * * *} \\
(0.04)\end{array}$ & $\begin{array}{l}0.839 * * * \\
(0.04)\end{array}$ & 0.45 & $\begin{array}{l}4.06 \\
(0.26) \\
\end{array}$ \\
\hline \multicolumn{10}{|l|}{ Hong Kong } \\
\hline $1995-2012$ & $\begin{array}{l}0.039 \\
(0.05)\end{array}$ & $\begin{array}{l}-0.258 \\
(0.30)\end{array}$ & $\begin{array}{l}-0.518^{* *} * \\
(0.24)\end{array}$ & $\begin{array}{l}-0.020 \\
(0.15)\end{array}$ & $\begin{array}{l}1.189 \text { *** } \\
(0.02)\end{array}$ & $\begin{array}{l}0.082^{* * * *} \\
(0.02)\end{array}$ & $\begin{array}{l}0.908 * * * \\
(0.02)\end{array}$ & 0.87 & $\begin{array}{l}5.23 \\
(0.16)\end{array}$ \\
\hline $1995-2003$ & $\begin{array}{l}0.037 \\
(0.07)\end{array}$ & $\begin{array}{l}-0.247 \\
(0.39)\end{array}$ & $\begin{array}{l}-0.536^{*} \\
(0.32)\end{array}$ & $\begin{array}{l}0.028 \\
(0.22)\end{array}$ & $\begin{array}{l}1.177^{* * *} * \\
(0.02)\end{array}$ & $\begin{array}{l}0.112 * * * \\
(0.03)\end{array}$ & $\begin{array}{l}0.858 * * * \\
(0.04)\end{array}$ & 0.86 & $\begin{array}{l}2.99 \\
(0.39)\end{array}$ \\
\hline 2004-2012 & $\begin{array}{l}0.046 \\
(0.06) \\
\end{array}$ & $\begin{array}{c}-0.596 \\
(0.42) \\
\end{array}$ & $\begin{array}{l}-0.521 \\
(0.38) \\
\end{array}$ & $\begin{array}{c}-0.086 \\
(0.20) \\
\end{array}$ & $\begin{array}{l}1.202^{* * *} * \\
(0.02)\end{array}$ & $\begin{array}{l}0.068 * * * \\
(0.03)\end{array}$ & $\begin{array}{l}0.917 * * * \\
(0.03)\end{array}$ & 0.88 & $\begin{array}{l}3.47 \\
(0.32) \\
\end{array}$ \\
\hline \multicolumn{10}{|l|}{ Japan } \\
\hline $1995-2012$ & $\begin{array}{l}0.180 * \\
(0.09)\end{array}$ & $\begin{array}{l}-0.277 \\
(0.96)\end{array}$ & $\begin{array}{l}3.777 * \\
(2.02)\end{array}$ & $\begin{array}{l}0.533 \\
(0.42)\end{array}$ & $\begin{array}{l}1.188 * * * \\
(0.04)\end{array}$ & $\begin{array}{l}0.079 * * * \\
(0.02)\end{array}$ & $\begin{array}{l}0.905 * * * \\
(0.02)\end{array}$ & 0.57 & $\begin{array}{l}5.78 \\
(0.12)\end{array}$ \\
\hline $1995-2003$ & $\begin{array}{l}0.159 \\
(0.16)\end{array}$ & $\begin{array}{l}-0.430 \\
(1.18)\end{array}$ & $\begin{array}{l}4.959 * * \\
(2.50)\end{array}$ & $\begin{array}{l}0.455 \\
(0.52)\end{array}$ & $\begin{array}{l}1.238 * * * \\
(0.06)\end{array}$ & $\begin{array}{l}0.096 * * \\
(0.04)\end{array}$ & $\begin{array}{l}0.877 * * * \\
(0.05)\end{array}$ & 0.47 & $\begin{array}{l}5.42 \\
(0.14)\end{array}$ \\
\hline 2004-2012 & $\begin{array}{l}0.187 * \\
(0.11)\end{array}$ & $\begin{array}{l}-0.239 \\
(1.43)\end{array}$ & $\begin{array}{l}0.261 \\
(3.41)\end{array}$ & $\begin{array}{l}0.403 \\
(0.74) \\
\end{array}$ & $\begin{array}{l}1.146^{* * * *} \\
(0.05)\end{array}$ & $\begin{array}{l}0.066^{* * *} \\
(0.03)\end{array}$ & $\begin{array}{l}0.909 * * * \\
(0.04)\end{array}$ & 0.68 & $\begin{array}{l}0.33 \\
(0.95) \\
\end{array}$ \\
\hline \multicolumn{10}{|l|}{ Singapore } \\
\hline $1995-2012$ & $\begin{array}{l}0.096 \\
(0.06)\end{array}$ & $\begin{array}{l}-1.246^{* *} \\
(0.61)\end{array}$ & $\begin{array}{l}-0.469 \\
(0.35)\end{array}$ & $\begin{array}{l}-0.125 \\
(0.14)\end{array}$ & $\begin{array}{l}1.100^{* * * *} \\
(0.03)\end{array}$ & $\begin{array}{l}0.095 * * * \\
(0.03)\end{array}$ & $\begin{array}{l}0.905^{* * * *} \\
(0.02)\end{array}$ & 0.66 & $\begin{array}{l}5.41 \\
(0.14)\end{array}$ \\
\hline $1995-2003$ & $\begin{array}{l}0.032 \\
(0.12)\end{array}$ & $\begin{array}{l}-1.144 \\
(0.74)\end{array}$ & $\begin{array}{l}-0.650 * \\
(0.39)\end{array}$ & $\begin{array}{c}-0.106 \\
(0.16)\end{array}$ & $\begin{array}{l}1.372 * * * \\
(0.04)\end{array}$ & $\begin{array}{l}0.075^{* *} \\
(0.03)\end{array}$ & $\begin{array}{l}0.923 * * * \\
(0.03)\end{array}$ & 0.67 & $\begin{array}{l}4.03 \\
(0.26)\end{array}$ \\
\hline 2004-2012 & $\begin{array}{l}0.125 * \\
(0.07)\end{array}$ & $\begin{array}{c}-1.018 \\
(0.96)\end{array}$ & $\begin{array}{l}0.066 \\
(0.68)\end{array}$ & $\begin{array}{c}-0.194 \\
(0.31)\end{array}$ & $\begin{array}{l}0.992 * * * \\
(0.04)\end{array}$ & $\begin{array}{l}0.097 * * * \\
(0.04)\end{array}$ & $\begin{array}{l}0.892 * * * \\
(0.03)\end{array}$ & 0.72 & $\begin{array}{l}2.76 \\
(0.43) \\
\end{array}$ \\
\hline
\end{tabular}

This table presents the GARCH model results for the model below, estimated over 1995-2012:

$r_{i, t}=\mu_{0, i}+\beta_{1, i} \cdot L_{i, t}+\beta_{2, i} \cdot \hat{s}_{i, t}+\beta_{3, i} \cdot \hat{c}_{i, t}+\beta_{4, i} \cdot r_{i, t}^{M}+\varepsilon_{i, t} ; \varepsilon_{i, t}=z_{i, t} \cdot \sigma_{i, t} ; \sigma_{i, t}^{2}=a_{0, i}+a_{1, i} \cdot \varepsilon_{i, t}^{2}+b_{1, i} \cdot \sigma_{i, t-1}^{2}$,

where $r_{i, t}$ and $r_{i, t}^{M}$ denote weekly logarithmic returns on the domestic listed real estate and stock market indexes respectively at time $t$.

$L_{i, t}, \hat{s}_{i, t}, \hat{c}_{i, t}$ denote the unexpected changes in the level, slope and curvature of domestic zero-coupon yield curve respectively, all calculated at time $t$ as the difference between the actual changes in the yield curve level/slope/curvature and ones forecasted via the appropriate specification of the ARMA model. $z_{i, t}$ is a sequence of independent, identically distributed random variables zero mean and unit variance, implying $\varepsilon_{i, t} \mid \boldsymbol{\Phi}_{i, t-1} \sim N\left(0, \sigma_{i, t}^{2}\right)$ is conditionally normal heteroscedastic error term, $\boldsymbol{\Phi}_{i, t-1}$ is the information set available at time $t-1 . \sigma_{i, t}^{2}$ is the conditional variance of the listed real estate index returns at time $t$. The table reports coefficient estimates alongside standard errors in parentheses. Wald test reports the $\chi^{2}$-statistics of the test for the joint significance of the interest rate factors (i.e. $\left.\beta_{1, i}=\beta_{2, i}=\beta_{3, i}=0\right)$ with $p$ values reported in parentheses. *,**,*** indicate significance at the $10 \%, 5 \%$ and $1 \%$ levels, respectively. 
Table 4: Multifactor model with augmented volatility equation

\begin{tabular}{|c|c|c|c|c|c|c|c|c|}
\hline \multicolumn{9}{|c|}{ a) $\mathbf{i r}_{i, t-1}=$} \\
\hline & $L_{i, t-1}$ & $\hat{s}_{i, t-1}$ & $\hat{c}_{i, t-1}$ & Wald & $h_{i, t-1}^{L}$ & $h_{i, t-1}^{S}$ & $h_{i, t-1}^{C}$ & Wald \\
\hline \multicolumn{9}{|l|}{$U S$} \\
\hline \multirow[t]{2}{*}{ 1995-2012 } & $1.273^{*}$ & 1.334 & $-0.511 * * *$ & $79.99 * * *$ & $-11.161 * *$ & 3.758 & -0.014 & $15.27 * * *$ \\
\hline & $(0.68)$ & $(0.86)$ & $(0.11)$ & $(0.00)$ & $(4.74)$ & $(2.73)$ & $(0.26)$ & $(0.00)$ \\
\hline \multirow[t]{2}{*}{$1995-2003$} & $1.404 * *$ & 0.922 & $-0.670 * * *$ & $33.83 * * *$ & $-54.296 * * *$ & $4.905 * * *$ & 0.031 & $63.36^{* * * *}$ \\
\hline & $(0.57)$ & $(0.87)$ & $(0.13)$ & $(0.00)$ & $(12.90)$ & $(1.85)$ & $(0.20)$ & $(0.00)$ \\
\hline \multirow[t]{2}{*}{ 2004-2012 } & $-4.292 * *$ & $-3.128 *$ & $-0.893 * * *$ & $38.73 * * *$ & $-12.132 *$ & $12.310^{*}$ & $-0.596^{*}$ & 4.88 \\
\hline & $(1.88)$ & $(1.65)$ & $(0.25)$ & $(0.00)$ & $(6.78)$ & $(6.68)$ & $(0.32)$ & $(0.18)$ \\
\hline \multicolumn{9}{|l|}{ Australia } \\
\hline \multirow[t]{2}{*}{$1995-2012$} & $-0.559 *$ & 0.951 & -0.143 & $9.64 * *$ & -1.510 & 0.407 & $-0.782 * *$ & 4.71 \\
\hline & $(0.30)$ & $(0.63)$ & $(0.22)$ & $(0.02)$ & (1.84) & $(0.49)$ & $(0.39)$ & $(0.19)$ \\
\hline \multirow[t]{2}{*}{$1995-2003$} & $-0.684 * *$ & $1.306^{*}$ & -0.102 & $15.20 * * *$ & 17.659 & 2.617 & 13.935 & 1.30 \\
\hline & $(0.31)$ & $(0.74)$ & $(0.29)$ & $(0.00)$ & $(31.53)$ & (4.09) & (14.61) & $(0.73)$ \\
\hline \multirow[t]{2}{*}{ 2004-2012 } & 0.309 & $-1.259 *$ & -0.267 & 5.15 & -6.679 & -0.095 & 0.023 & 1.43 \\
\hline & $(0.85)$ & $(0.67)$ & $(0.39)$ & $(0.16)$ & $(7.95)$ & $(0.59)$ & $(0.65)$ & $(0.70)$ \\
\hline$U K$ & UK & & & & & & & \\
\hline \multirow[t]{2}{*}{$1995-2012$} & $-2.849 * * *$ & 0.867 & $-0.457 * *$ & $46.31 * * *$ & 4.873 & 6.633 & 0.381 & 2.50 \\
\hline & $(0.87)$ & $(0.98)$ & $(0.19)$ & $(0.00)$ & (12.12) & $(5.86)$ & (0.99) & $(0.47)$ \\
\hline \multirow[t]{2}{*}{$1995-2003$} & $-3.352 * * *$ & $1.695 *$ & $-0.355^{* *}$ & $46.69 * * *$ & 15.759 & -4.025 & 0.783 & 3.38 \\
\hline & $(0.87)$ & $(1.02)$ & $(0.17)$ & $(0.00)$ & (19.97) & $(3.87)$ & $(2.58)$ & $(0.34)$ \\
\hline \multirow[t]{2}{*}{ 2004-2012 } & 11.017 & $-11.982 * *$ & $-3.274 *$ & $99.77 * * *$ & -2.328 & 31.733 & 3.561 & 2.64 \\
\hline & $(7.77)$ & $(6.03)$ & $(1.72)$ & $(0.00)$ & (14.04) & $(20.88)$ & $(2.68)$ & $(0.45)$ \\
\hline \multicolumn{9}{|l|}{ Hong Kong } \\
\hline \multirow[t]{2}{*}{$1995-2012$} & -0.372 & -0.051 & 0.042 & 1.25 & 0.526 & 0.170 & -0.099 & 2.54 \\
\hline & $(0.34)$ & $(0.26)$ & $(0.14)$ & $(0.74)$ & $(0.53)$ & (0.19) & $(0.26)$ & $(0.47)$ \\
\hline \multirow[t]{2}{*}{$1995-2003$} & -0.511 & $0.518 * * *$ & $0.320 * *$ & $50.92 * * *$ & -6.693 & 0.096 & 1.186 & 3.18 \\
\hline & $(0.37)$ & $(0.17)$ & $(0.14)$ & $(0.00)$ & $(4.17)$ & $(0.45)$ & $(1.18)$ & $(0.37)$ \\
\hline \multirow[t]{2}{*}{ 2004-2012 } & -0.358 & $-0.501 * *$ & -0.093 & $27.07 * * *$ & 3.919 & $0.663 * * *$ & $-0.656^{* * *} *$ & $10.03 * *$ \\
\hline & $(0.26)$ & $(0.20)$ & $(0.13)$ & $(0.00)$ & $(3.41)$ & $(0.24)$ & $(0.24)$ & $(0.02)$ \\
\hline \multicolumn{9}{|l|}{ Japan } \\
\hline \multirow[t]{2}{*}{$1995-2012$} & -1.561 & -2.570 & 0.035 & 0.97 & 1.345 & -41.345 & 1.909 & 2.54 \\
\hline & $(2.27)$ & (3.38) & $(0.82)$ & $(0.81)$ & (3.11) & $(27.20)$ & (1.58) & $(0.47)$ \\
\hline \multirow[t]{2}{*}{$1995-2003$} & -0.546 & 4.296 & $2.108 * *$ & $24.70 * * *$ & 2.666 & -13.715 & -1.593 & 4.22 \\
\hline & (3.14) & $(4.31)$ & $(0.98)$ & $(0.00)$ & $(5.47)$ & $(52.43)$ & $(2.80)$ & $(0.24)$ \\
\hline \multirow[t]{2}{*}{ 2004-2012 } & $-6.537 * * *$ & $-4.701 *$ & 0.431 & $22.63 * * *$ & $-43.074 * *$ & 166.709 & 3.526 & 5.97 \\
\hline & (1.69) & $(2.85)$ & $(0.73)$ & $(0.00)$ & $(19.00)$ & (148.90) & $(3.66)$ & $(0.11)$ \\
\hline \multicolumn{9}{|l|}{ Singapore } \\
\hline \multirow[t]{2}{*}{$1995-2012$} & -2.402 & -2.541 & -0.572 & $33.21 * * *$ & 0.059 & 1.557 *** & -0.033 & $9.84 * *$ \\
\hline & $(2.56)$ & $(2.60)$ & $(0.42)$ & $(0.00)$ & $(0.40)$ & $(0.53)$ & $(0.04)$ & $(0.02)$ \\
\hline \multirow[t]{2}{*}{$1995-2003$} & -2.988 & $-3.129 * *$ & -0.752 & $60.21 * * *$ & $-0.308 * *$ & $0.928 * *$ & 0.014 & 5.74 \\
\hline & $(2.53)$ & $(1.36)$ & $(0.48)$ & $(0.00)$ & $(0.16)$ & $(0.44)$ & $(0.01)$ & $(0.13)$ \\
\hline 2004-2012 & -0.206 & 0.159 & 0.158 & 1.21 & 2.442 & 6.110 & $-4.771 * * *$ & $39.07 * * *$ \\
\hline & (1.16) & $(0.92)$ & $(0.24)$ & $(0.75)$ & $(21.60)$ & $(17.76)$ & $(1.77)$ & $(0.00)$ \\
\hline
\end{tabular}

This table presents the GARCH model results for the model below, estimated over 1995-2012:

$r_{i, t}=\mu_{0, i}+\beta_{1, i} \cdot L_{i, t}+\beta_{2, i} \cdot \hat{s}_{i, t}+\beta_{3, i} \cdot \hat{c}_{i, t}+\beta_{4, i} \cdot r_{i, t}^{M}+\varepsilon_{i, t} ; \varepsilon_{i, t}=z_{i, t} \cdot \sigma_{i, t} ; \sigma_{i, t}^{2}=a_{0, i}+a_{1, i} \cdot \varepsilon_{i, t}^{2}+b_{1, i} \cdot \sigma_{i, t-1}^{2}+\mathbf{g}^{\prime} \cdot \mathbf{X}_{i, t-1}$,

where $r_{i, t}$ and $r_{i, t}^{M}$ denote weekly logarithmic returns on the domestic securitised real estate and stock market indexes respectively at time $t$.

$L_{i, t}, \hat{s}_{i, t}, \hat{c}_{i, t}$ denote the unexpected changes in the level, slope and curvature of domestic zero-coupon yield curve respectively, all calculated at time $t$ as the difference between the actual changes in the yield curve level/slope/curvature and ones forecasted via the appropriate specification of the ARMA model. $z_{i, t}$ is a sequence of independent, identically distributed random variables zero mean and unit variance, implying $\varepsilon_{i, t} \mid \boldsymbol{\Phi}_{i, t-1} \sim N\left(0, \sigma_{i, t}^{2}\right)$ is conditionally normal heteroscedastic error term, $\boldsymbol{\Phi}_{i, t-1}$ is the information set available at time $t-1 . \sigma_{i, t}^{2}$ is the conditional variance of the listed real estate index returns at time $t$. The volatility equation for securitised real estate is interchangeably augmented in two alternative ways using the vector of the interest rate factors $\mathbf{X}_{i, t}$ :

a) $\mathbf{X}_{i, t-1}=\mathbf{i r}_{i, t-1}=\left\{L_{i, t-1}, \hat{s}_{i, t-1}, \hat{c}_{i, t-1}\right\}$

b) $\mathbf{X}_{i, t-1}=\mathbf{h}_{i, t-1}^{i r}=\left\{h_{i, t-1}^{L}, h_{i, t-1}^{S}, h_{i, t-1}^{C}\right\}$

The table reports coefficient estimates alongside standard errors in parentheses. Wald test reports the $\chi^{2}$-statistics of the test for the joint significance of the interest rate factors (i.e. $g_{1, t}=g_{2, t}=g_{3, t}=0$ ) with $p$-values reported in parentheses. *,**,*** indicate significance at the $10 \%, 5 \%$ and $1 \%$ levels, respectively. 
Table 5: The asymmetric response tests of the yield curve factors - Sign response regression results

\begin{tabular}{|c|c|c|c|c|c|c|c|c|c|c|}
\hline & $L^{+}$ & $L^{-}$ & Wald $L$ & $S^{+}$ & $S^{-}$ & Wald $S$ & $C^{+}$ & $C^{-}$ & Wald $C$ & Adj. $R^{2}$ \\
\hline \multirow[t]{2}{*}{ US returns } & -1.034 & -1.146 & 0.112 & $-2.060 * *$ & -1.105 & -0.955 & $-0.386 * * *$ & 0.291 & $-0.677 * *$ & 0.43 \\
\hline & $(1.50)$ & (1.21) & $(0.00)$ & $(0.98)$ & (1.39) & $(0.27)$ & $(0.12)$ & $(0.25)$ & $(4.03)$ & \\
\hline US variance & $-3.455 * * *$ & $3.922 * *$ & $-7.377 * * *$ & $3.046^{* *} *$ & -0.116 & 3.162 & -0.103 & -0.257 & 0.154 & \\
\hline \multirow[t]{2}{*}{ AU returns } & $-1.719 * *$ & -0.687 & -1.032 & $1.265^{* *} *$ & -1.103 & $2.368 * *$ & $-0.802 * * *$ & 0.147 & $-0.949 * *$ & 0.39 \\
\hline & $(0.78)$ & $(0.75)$ & $(0.74)$ & $(0.63)$ & $(0.78)$ & $(4.44)$ & $(0.27)$ & $(0.28)$ & $(4.26)$ & \\
\hline AU variance & -0.377 & 0.109 & -0.485 & -0.162 & $1.189^{*}$ & -1.351 & 0.212 & -0.617 & 0.830 & \\
\hline \multirow[t]{2}{*}{ UK returns } & -0.320 & -1.347 & 1.027 & -1.692 & 0.216 & -1.908 & -0.152 & 0.373 & -0.525 & 0.32 \\
\hline & (1.34) & (1.47) & $(0.23)$ & (1.15) & (1.08) & $(1.21)$ & $(0.31)$ & $(0.35)$ & $(0.91)$ & \\
\hline \multirow[t]{2}{*}{ UK variance } & -3.163 & -0.702 & -2.461 & 1.859 & -0.069 & 1.928 & 0.132 & $-1.450 * *$ & $1.582 * *$ & \\
\hline & $(2.37)$ & $(2.02)$ & $(0.50)$ & $(1.95)$ & $(1.77)$ & $(0.36)$ & $(0.27)$ & $(0.66)$ & $(4.34)$ & \\
\hline \multirow[t]{2}{*}{ Hk returns } & -0.798 & -0.523 & -0.275 & $-0.498^{*}$ & -0.571 & 0.073 & -0.246 & 0.128 & -0.373 & 0.87 \\
\hline & $(0.59)$ & $(0.66)$ & $(0.07)$ & $(0.30)$ & $(0.42)$ & $(0.02)$ & $(0.21)$ & $(0.26)$ & $(0.96)$ & \\
\hline \multirow[t]{2}{*}{ Hk variance } & $-0.873^{*}$ & -0.135 & -0.738 & 0.521 & -0.530 & $1.051 *$ & -0.014 & -0.110 & 0.096 & \\
\hline & $(0.50)$ & $(0.35)$ & $(1.73)$ & $(0.37)$ & $(0.43)$ & $(2.91)$ & $(0.22)$ & $(0.24)$ & $(0.06)$ & \\
\hline JP returns & (3.47) & $(3.32)$ & $(0.00)$ & (3.69) & (3.15) & $(0.65)$ & $(0.70)$ & $(0.63)$ & (1.49) & \\
\hline \multirow[t]{2}{*}{ JP variance } & -3.548 & -3.744 & 0.196 & -1.393 & -0.949 & -0.444 & 1.034 & -1.092 & 2.127 & \\
\hline & $(6.54)$ & $(6.63)$ & $(0.00)$ & $(6.25)$ & $(5.38)$ & $(0.00)$ & $(1.02)$ & $(1.45)$ & $(1.41)$ & \\
\hline \multirow[t]{2}{*}{ SG returns } & -1.293 & -0.889 & -0.404 & -0.081 & -0.610 & 0.529 & -0.210 & 0.156 & -0.366 & 0.66 \\
\hline & $(0.85)$ & $(0.97)$ & (0.09) & $(0.67)$ & $(0.59)$ & $(0.28)$ & $(0.21)$ & $(0.35)$ & $(0.71)$ & \\
\hline \multirow[t]{2}{*}{ SG variance } & -0.297 & -0.575 & 0.278 & 0.860 & -0.686 & 1.546 & 0.196 & 0.126 & 0.070 & \\
\hline & $(0.98)$ & $(0.83)$ & $(0.06)$ & $(0.68)$ & $(0.90)$ & $(1.80)$ & $(0.33)$ & $(0.27)$ & $(0.02)$ & \\
\hline
\end{tabular}

This table reports the results of the following GARCH model estimated over 1995-2012:

$$
r_{i, t}=\mu_{0, i}+\beta_{1, i}^{+} \cdot L_{i, t} \cdot D_{i, t}^{L+}+\beta_{1, i}^{-} \cdot L_{i, t} \cdot D_{i, t}^{L-}+\beta_{2, i}^{+} \cdot S_{i, t} \cdot D_{i, t}^{S+}+\beta_{2, i}^{-} \cdot S_{i, t} \cdot D_{i, t}^{S-}+
$$

$$
+\beta_{3, i}^{+} \cdot C_{i, t} \cdot D_{i, t}^{C+}+\beta_{3, i}^{-} \cdot C_{i, t} \cdot D_{i, t}^{C-}+\psi \cdot r_{i, t}^{M}+\varepsilon_{i, t}
$$

where error term using the information set $\mathbf{\Omega}$ for country $i$ available at time $t-1$ is conditionally normal and heteroscedastic and expressed as $\varepsilon_{i, t}=z_{i, t} \cdot \sigma_{i, t}$ and $\varepsilon_{i, t} \mid \boldsymbol{\Omega}_{i, t-1} \sim N\left(0, \sigma_{i, t}^{2}\right) .\left\{z_{i, t}\right\}$ is a sequence of independent, identically distributed random variables zero mean and unit

variance. $r_{i, t}$ and $r_{i, t}^{M}$ denote weekly logarithmic price changes on the domestic securitised real estate and stock market indexes respectively at time $t$. Variables $L, S$, and $C$ are the unexpected changes in the yield curve level, slope and curvature, all calculated at time $t$ as the difference between the actual changes in the yield curve level/slope/curvature and ones forecasted via the appropriate specification of the ARMA model. Dummy variables $D_{i, t}^{+}$and $D_{i, t}^{-}$take the value of one when there is a positive or negative change in the yield curve factor respectively. The volatility equation for securitised real estate is specified as:

$$
\begin{aligned}
\sigma_{i, t}^{2}=a_{0, i}+ & a_{1, i} \cdot \varepsilon_{i, t-1}^{2}+b_{1, i} \cdot \sigma_{i, t-1}^{2}+g_{1, i}^{+} \cdot L_{i, t-1} \cdot D_{i, t-1}^{L+}+g_{1, i}^{-} \cdot L_{i, t-1} \cdot D_{i, t-1}^{L-}+ \\
& +g_{2, i}^{+} \cdot S_{i, t-1} \cdot D_{i, t-1}^{S+}+g_{2, i}^{-} \cdot S_{i, t-1} \cdot D_{i, t-1}^{S-}+g_{3, i}^{+} \cdot C_{i, t-1} \cdot D_{i, t-1}^{C+}+g_{3, i}^{-} \cdot C_{i, t-1} \cdot D_{i, t-1}^{C-}
\end{aligned}
$$

The table reports coefficient estimates alongside standard errors in parentheses. The asymmetric effect of the positive and negative interest rate changes is tested using Wald tests of the form $\beta_{n, i}^{+}-\beta_{n, i}^{-}=0$ for price changes, and $g_{n, i}^{+}-g_{n, i}^{-}=0$ for the impact on volatility respectively, with $\chi^{2}$-statistics of the tests reported in parentheses. *, **, *** indicate significance at the $10 \%, 5 \%$ and $1 \%$ levels, respectively. 
Table 6: The asymmetric response tests of the yield curve factors - Size response regression results

\begin{tabular}{|c|c|c|c|c|c|c|c|c|c|c|}
\hline & $L^{b i g}$ & $L^{\text {small }}$ & Wald $L$ & $S^{b i g}$ & $S^{\text {small }}$ & Wald $S$ & $C^{\text {big }}$ & $C^{\text {small }}$ & Wald $C$ & Adj. $R^{2}$ \\
\hline \multirow[t]{2}{*}{ US returns } & -1.104 & 0.032 & -1.137 & $-1.679 *$ & -1.862 & 0.183 & -0.114 & 0.880 & -0.994 & 0.42 \\
\hline & $(0.93)$ & (1.78) & $(0.55)$ & $(1.00)$ & (1.64) & $(0.02)$ & $(0.15)$ & $(0.61)$ & $(2.45)$ & \\
\hline \multirow[t]{2}{*}{ US variance } & 1.469 & -0.197 & 1.666 & 1.207 & 1.626 & -0.419 & $-0.595 * * *$ & -0.146 & -0.449 & \\
\hline & $(1.35)$ & $(3.47)$ & $(0.51)$ & $(1.26)$ & $(2.68)$ & $(0.06)$ & $(0.13)$ & $(0.92)$ & $(0.24)$ & \\
\hline \multirow[t]{2}{*}{ AU returns } & $-1.927 * * *$ & -0.154 & -1.774 & -0.581 & 1.877 & $-2.457 * *$ & $-0.672 * *$ & 0.229 & -0.901 & 0.41 \\
\hline & $(0.58)$ & (1.39) & $(1.73)$ & $(0.61)$ & $(1.22)$ & $(4.42)^{* *}$ & $(0.29)$ & $(0.66)$ & $(1.60)$ & \\
\hline AU variance & 2.425 & -9.287 & $11.712 * * *$ & -2.829 & $10.348 * *$ & $-13.177 * * *$ & -1.747 & $-6.643 * * *$ & $4.896^{* * *}$ & \\
\hline \multirow[t]{2}{*}{ UK returns } & -0.922 & 0.176 & -1.098 & -0.567 & -3.272 & 2.705 & 0.079 & -0.366 & 0.445 & 0.31 \\
\hline & $(0.84)$ & $(2.36)$ & $(0.23)$ & $(0.65)$ & $(2.05)$ & $(1.91)$ & $(0.16)$ & $(0.70)$ & $(0.40)$ & \\
\hline \multirow[t]{2}{*}{ UK variance } & $-3.003 *$ & 0.023 & -3.027 & 0.947 & $-4.997 * *$ & $5.944 * *$ & $-0.379 *$ & $-3.555 * * *$ & $3.176 * * *$ & \\
\hline & $(1.57)$ & (1.90) & (1.57) & (1.02) & $(2.48)$ & $(5.49)$ & $(0.21)$ & $(0.71)$ & $(21.03)$ & \\
\hline \multirow[t]{2}{*}{ Hk returns } & -0.514 & $-3.295^{*} *$ & $2.781 * *$ & $-0.570^{* *}$ & 0.185 & -0.755 & -0.075 & 0.422 & -0.497 & 0.87 \\
\hline & $(0.35)$ & (1.39) & $(3.85)$ & $(0.23)$ & (1.12) & $(0.45)$ & $(0.15)$ & $(0.60)$ & $(0.63)$ & \\
\hline \multirow[t]{2}{*}{$\mathrm{Hk}$ variance } & -0.444 & $-3.153 * * *$ & $2.708^{*} *$ & -0.046 & -0.434 & 0.388 & 0.010 & -0.624 & 0.634 & \\
\hline & $(0.34)$ & (1.07) & $(5.00)$ & $(0.22)$ & $(0.76)$ & $(0.21)$ & $(0.15)$ & $(0.46)$ & $(1.95)$ & \\
\hline JP returns & $(2.40)$ & (6.88) & $(0.62)$ & $(2.22)$ & $(5.47)$ & $(0.35)$ & $(0.45)$ & $(2.47)$ & $(0.27)$ & \\
\hline \multirow[t]{2}{*}{ JP variance } & -2.275 & -1.289 & -0.986 & -0.917 & -3.583 & 2.666 & 0.387 & -5.813 & 6.200 & \\
\hline & $(3.62)$ & (13.81) & $(0.01)$ & $(2.91)$ & (14.79) & (0.04) & $(0.84)$ & $(6.78)$ & $(0.82)$ & \\
\hline \multirow[t]{2}{*}{ SG returns } & $-1.454 * *$ & 3.667 & $-5.121 * *$ & $-1.051 * * *$ & 3.680 & $-4.731 * *$ & -0.198 & -1.474 & 1.277 & 0.67 \\
\hline & $(0.58)$ & $(2.61)$ & $(3.94)$ & $(0.33)$ & $(2.34)$ & $(4.14)^{* *}$ & $(0.14)$ & (1.20) & (1.11) & \\
\hline \multirow[t]{2}{*}{ SG variance } & -2.622 & -11.450 & 8.828 & -1.263 & $-11.594 * *$ & $10.330 * *$ & $-0.785 * * *$ & -4.205 & 3.420 & \\
\hline & $(1.72)$ & $(7.74)$ & $(1.25)$ & (1.10) & $(4.50)$ & $(4.05)$ & $(0.30)$ & $(5.42)$ & $(0.40)$ & \\
\hline
\end{tabular}

This table reports the results of the following GARCH model estimated over 1995-2012:

$r_{i, t}=\mu_{0, i}+\beta_{1, i}^{\text {big }} \cdot L_{i, t} \cdot D_{L, i, t}^{\text {big }}+\beta_{1, i}^{\text {small }} \cdot L_{i, t} \cdot D_{L, i, t}^{\text {small }}+\beta_{2, i}^{\text {big }} \cdot S_{i, t} \cdot D_{S, i, t}^{\text {big }}+\beta_{2, i}^{\text {small }} \cdot S_{i, t} \cdot D_{S, i, t}^{\text {small }}+$

$$
+\beta_{3, i}^{\text {big }} \cdot C_{i, t} \cdot D_{C, i, t}^{\text {big }}+\beta_{3, i}^{\text {small }} \cdot C_{i, t} \cdot D_{C, i, t}^{\text {small }}+\psi \cdot r_{i, t}^{M}+\varepsilon_{i, t}
$$

where error term using the information set $\mathbf{\Omega}$ for country $i$ available at time $t-1$ is conditionally normal and heteroscedastic and expressed as $\varepsilon_{i, t}=z_{i, t} \cdot \sigma_{i, t}$ and $\varepsilon_{i, t} \mid \boldsymbol{\Omega}_{i, t-1} \sim N\left(0, \sigma_{i, t}^{2}\right) .\left\{z_{i, t}\right\}$ is a sequence of independent, identically distributed random variables zero mean and unit

variance. $r_{i, t}$ and $r_{i, t}^{M}$ denote weekly logarithmic price changes on the domestic securitised real estate and stock market indexes respectively at time $t$. Variables $L, S$, and $C$ are the unexpected changes in the yield curve level, slope and curvature, all calculated at time $t$ as the difference between the actual changes in the yield curve level/slope/curvature and ones forecasted via the appropriate specification of the ARMA model. Dummy variables $D_{i, t}^{\text {big }}$ and $D_{i, t}^{\text {small }}$ take the value of one when there is a larger than median or smaller than median change in the yield curve factor respectively. The volatility equation for securitised real estate is specified as:

$$
\begin{aligned}
\sigma_{i, t}^{2}=a_{0, i}+ & a_{1, i} \cdot \varepsilon_{i, t-1}^{2}+b_{1, i} \cdot \sigma_{i, t-1}^{2}+g_{1, i}^{\text {big }} \cdot L_{i, t-1} \cdot D_{L, i, t-1}^{\text {big }}+g_{1, i}^{\text {small }} \cdot L_{i, t-1} \cdot D_{L, i, t-1}^{\text {small }}+ \\
& +g_{2, i}^{\text {big }} \cdot S_{i, t-1} \cdot D_{S, i, t-1}^{\text {big }}+g_{2, i}^{\text {small }} \cdot S_{i, t-1} \cdot D_{S, i, t-1}^{\text {small }}+g_{3, i}^{\text {big }} \cdot C_{i, t-1} \cdot D_{C, i, t-1}^{\text {big }}+g_{3, i}^{\text {small }} \cdot C_{i, t-1} \cdot D_{C, i, t-1}^{\text {small }}
\end{aligned}
$$

The table reports coefficient estimates alongside standard errors in parentheses. The asymmetric effect of the large and small interest rate changes is tested using Wald tests of the form $\beta_{n, i}^{\text {big }}-\beta_{n, i}^{\text {small }}=0$ for price changes, and $g_{n, i}^{\text {big }}-g_{n, i}^{\text {small }}=0$ for the impact on volatility respectively, with $\chi^{2}$ statistics of the tests reported in parentheses. $*, * *, * * *$ indicate significance at the $10 \%, 5 \%$ and $1 \%$ levels, respectively. 
Table 7: Robustness check - GARCH Multifactor model results

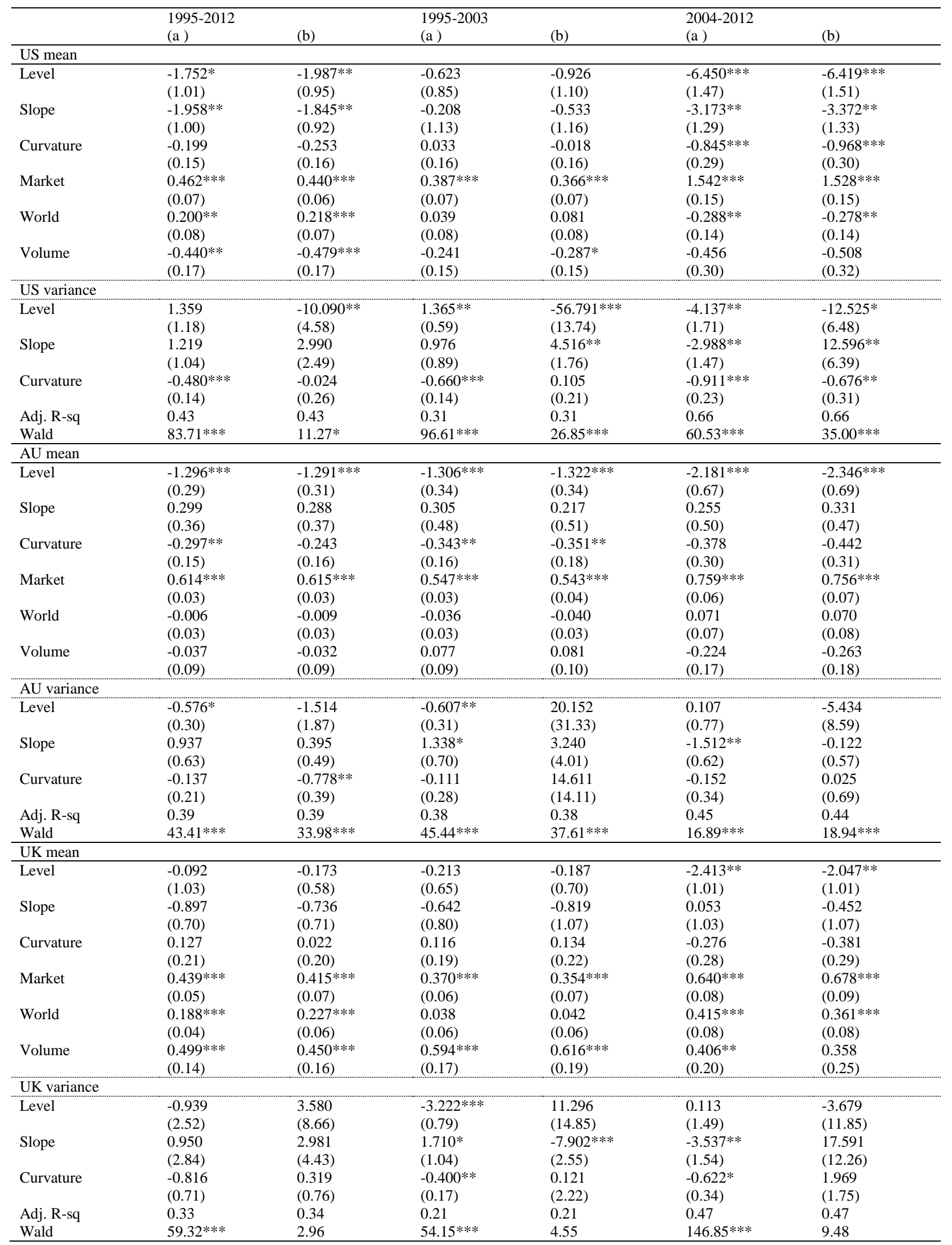


Table 7: Robustness check - GARCH Multifactor model results (continued)

\begin{tabular}{|c|c|c|c|c|c|c|}
\hline & $\begin{array}{l}1995-2012 \\
\text { (a ) }\end{array}$ & (b) & $\begin{array}{l}1995-2003 \\
\text { (a ) }\end{array}$ & (b) & $\begin{array}{l}2004-2012 \\
\text { (a ) }\end{array}$ & (b) \\
\hline \multicolumn{7}{|l|}{ HK mean } \\
\hline Level & -0.248 & -0.246 & -0.234 & -0.343 & -0.431 & -0.605 \\
\hline \multirow{2}{*}{ Slope } & $-0.500 * *$ & $-0.493 * *$ & $-0.474 *$ & $-0.417 *$ & -0.480 & $-0.768 * *$ \\
\hline & $(0.23)$ & $(0.22)$ & $(0.27)$ & $(0.24)$ & $(0.32)$ & $(0.32)$ \\
\hline Curvature & -0.035 & -0.023 & -0.104 & -0.042 & -0.162 & -0.146 \\
\hline \multirow[t]{2}{*}{ Market } & $1.200 * * *$ & $1.196^{* * * *}$ & $1.168 * * *$ & $1.159 * * *$ & $1.231 * * *$ & $1.253^{* * *}$ \\
\hline & $(0.02)$ & $(0.02)$ & $(0.03)$ & $(0.03)$ & $(0.03)$ & $(0.02)$ \\
\hline \multirow[t]{2}{*}{ World } & -0.030 & -0.028 & -0.017 & -0.012 & -0.052 & $-0.086 * * *$ \\
\hline & $(0.03)$ & $(0.03)$ & $(0.04)$ & $(0.05)$ & $(0.04)$ & $(0.03)$ \\
\hline \multirow[t]{2}{*}{ Volume } & $0.178 * *$ & $0.186^{* * *}$ & $0.329 * * *$ & $0.296^{* * *}$ & 0.101 & 0.067 \\
\hline & $(0.09)$ & $(0.09)$ & $(0.11)$ & $(0.12)$ & $(0.13)$ & $(0.14)$ \\
\hline \multicolumn{7}{|c|}{ HK variance } \\
\hline Level & -0.367 & 0.444 & -0.615 & -5.801 & -0.322 & 14.063 \\
\hline \multirow[t]{2}{*}{ Slope } & -0.084 & 0.162 & -0.178 & 0.214 & $-0.479 * *$ & $-1.090 * * *$ \\
\hline & $(0.26)$ & $(0.20)$ & $(0.59)$ & $(0.48)$ & $(0.20)$ & $(0.14)$ \\
\hline \multirow[t]{2}{*}{ Curvature } & 0.054 & -0.065 & $0.558 * *$ & 0.881 & -0.088 & $3.211^{* *} *$ \\
\hline & $(0.14)$ & $(0.27)$ & $(0.27)$ & (1.16) & $(0.14)$ & $(1.41)$ \\
\hline Adj. R-sq & 0.87 & 0.87 & 0.86 & 0.86 & 0.88 & 0.88 \\
\hline Wald & 6.11 & 7.66 & $56.70 * * *$ & 4.00 & $27.59 * * *$ & $12.42^{*}$ \\
\hline \multicolumn{7}{|l|}{ JP mean } \\
\hline Level & -0.413 & -0.508 & -1.103 & -0.767 & 0.238 & -0.494 \\
\hline & $(0.93)$ & $(0.94)$ & $(0.94)$ & (1.11) & (1.32) & $(1.31)$ \\
\hline Slope & 2.226 & 2.571 & 2.264 & 3.972 & 0.116 & 0.878 \\
\hline & (2.11) & (2.12) & (1.79) & $(2.68)$ & $(3.45)$ & (3.43) \\
\hline Curvature & 0.289 & 0.362 & -0.087 & 0.121 & 0.355 & 0.332 \\
\hline & $(0.44)$ & $(0.46)$ & $(0.46)$ & $(0.56)$ & $(0.71)$ & $(0.80)$ \\
\hline Market & $1.209 * * *$ & $1.206^{* * *}$ & $1.230 * * *$ & $1.236^{* * *}$ & $1.130 * * *$ & $1.130 * * *$ \\
\hline & $(0.04)$ & $(0.04)$ & $(0.06)$ & $(0.07)$ & $(0.06)$ & $(0.06)$ \\
\hline World & -0.061 & -0.057 & -0.136 & $-0.174 * *$ & 0.030 & 0.024 \\
\hline & $(0.22)$ & $(0.21)$ & $(0.37)$ & $(0.35)$ & $(0.26)$ & $(0.28)$ \\
\hline $\mathrm{JP}$ variance & & & & & & \\
\hline Level & -1.484 & 0.928 & 0.257 & -0.093 & $-5.818 * * *$ & $-40.617 * *$ \\
\hline & $(2.10)$ & $(3.13)$ & $(4.89)$ & $(4.57)$ & $(1.87)$ & $(18.24)$ \\
\hline Slope & -3.782 & -13.659 & $-10.345^{* *}$ & 7.710 & $-5.126^{*}$ & 149.625 \\
\hline & (3.38) & (28.34) & $(4.61)$ & $(45.28)$ & (2.63) & (138.71) \\
\hline Curvature & 0.351 & 0.612 & $5.283^{*} * *$ & -1.309 & 0.500 & 3.897 \\
\hline & $(0.81)$ & $(1.30)$ & $(0.88)$ & $(2.23)$ & $(0.67)$ & (3.66) \\
\hline Adj. R-sq & 0.58 & 0.58 & 0.50 & 0.50 & 0.69 & 0.69 \\
\hline Wald & 5.28 & $13.16^{* * *}$ & $32.81 * * *$ & $19.20 * * *$ & $23.62 * * *$ & 6.70 \\
\hline SG mean & & & & & & \\
\hline Level & -0.831 & $-1.071 *$ & $-1.554 * *$ & $-1.298 *$ & -1.164 & -0.843 \\
\hline & $(0.59)$ & $(0.59)$ & $(0.78)$ & $(0.72)$ & (1.14) & $(0.89)$ \\
\hline Slope & $-0.758 * *$ & -0.322 & $-1.010 * *$ & $-0.677^{*}$ & -0.177 & 0.231 \\
\hline & $(0.36)$ & $(0.34)$ & $(0.42)$ & $(0.36)$ & $(0.86)$ & $(0.69)$ \\
\hline Curvature & -0.094 & -0.065 & -0.241 & -0.121 & -0.150 & -0.119 \\
\hline & $(0.13)$ & $(0.13)$ & $(0.18)$ & $(0.14)$ & $(0.18)$ & $(0.29)$ \\
\hline Market & $1.184 * * *$ & $1.120 * * *$ & $1.309 * * *$ & $1.353 * * *$ & $1.001 * * *$ & $0.965^{* * *}$ \\
\hline & $(0.04)$ & $(0.03)$ & $(0.06)$ & $(0.05)$ & $(0.06)$ & $(0.04)$ \\
\hline World & -0.022 & -0.044 & $0.150 *$ & 0.032 & 0.091 & 0.030 \\
\hline & $(0.04)$ & $(0.04)$ & $(0.09)$ & $(0.07)$ & $(0.06)$ & $(0.05)$ \\
\hline Volume & $0.261 * *$ & $0.226^{*}$ & $0.651 * *$ & 0.223 & 0.111 & 0.134 \\
\hline & $(0.13)$ & $(0.12)$ & $(0.27)$ & $(0.23)$ & $(0.15)$ & $(0.14)$ \\
\hline SG varianc & & & & & & \\
\hline Level & -2.105 & 0.063 & $-6.296 * * *$ & -0.064 & $-3.198 * *$ & -2.241 \\
\hline & $(1.90)$ & $(0.40)$ & $(1.92)$ & $(0.18)$ & $(1.43)$ & $(4.00)$ \\
\hline Slope & -1.128 & $1.543^{* * *}$ & $-4.235^{* * *} *$ & $0.927 * * *$ & 1.243 & $10.303 * * *$ \\
\hline & (1.11) & $(0.53)$ & $(1.40)$ & $(0.29)$ & (1.69) & $(3.28)$ \\
\hline Curvature & $-0.627 *$ & -0.034 & $-1.378 * * *$ & -0.007 & $-1.353 * *$ & $-3.709 * * *$ \\
\hline & $(0.33)$ & $(0.04)$ & $(0.34)$ & $(0.01)$ & $(0.63)$ & $(0.73)$ \\
\hline Adj. R-sq & 0.67 & 0.66 & 0.67 & 0.67 & 0.72 & 0.71 \\
\hline Wald & $142.70 * * *$ & $15.14 * *$ & $84.32 * * *$ & $18.22 * * *$ & 3.25 & $230.86 * * *$ \\
\hline
\end{tabular}


This table presents the GARCH model results for the model below, estimated over 1995-2012:

$r_{i, t}=\mu_{0, i}+\beta_{1, i} \cdot L_{i, t}+\beta_{2, i} \cdot \hat{s}_{i, t}+\beta_{3, i} \cdot \hat{c}_{i, t}+\beta_{4, i} \cdot r_{i, t}^{M}+\beta_{5, i} \cdot r_{i, t}^{W}+\beta_{6, i} \cdot \operatorname{vol}_{i, t}+\varepsilon_{i, t} ; \varepsilon_{i, t}=z_{i, t} \cdot \sigma_{i, t} ; \sigma_{i, t}^{2}=a_{0, i}+a_{1, i} \cdot \varepsilon_{i, t}^{2}+b_{1, i} \cdot \sigma_{i, t-1}^{2}+\mathbf{g}^{\prime} \cdot \mathbf{X}_{i, t-1}$,

where $r_{i, t}, r_{i, t}^{M}$ and $r_{i, t}^{W}$ denote weekly logarithmic changes in the domestic securitised real estate, stock market and MSCI world price indexes

respectively at time $t . L_{i, t}, \hat{s}_{i, t}, \hat{c}_{i, t}$ denote the unexpected changes in the level, slope and curvature of domestic zero-coupon yield curve

respectively, all calculated at time $t$ as the difference between the actual changes in the yield curve level/slope/curvature and ones forecasted via the appropriate specification of the ARMA model. $z_{i, t}$ is a sequence of independent, identically distributed random variables zero mean and unit variance, implying $\varepsilon_{i, t} \mid \boldsymbol{\Phi}_{i, t-1} \sim N\left(0, \sigma_{i, t}^{2}\right)$ is conditionally normal heteroscedastic error term, $\boldsymbol{\Phi}_{i, t-1}$ is the information set available at time $t-1$. $\sigma_{i, t}^{2}$ is the conditional variance of the listed real estate index returns at time $t$. The volatility equation for securitised real estate is interchangeably augmented in two alternative ways using the vector of the interest rate factors $\mathbf{X}_{i, t-1}$ :

a) $\mathbf{X}_{i, t-1}=\mathbf{i r}_{i, t-1}=\left\{L_{i, t-1}, \hat{s}_{i, t-1}, \hat{c}_{i, t-1}\right\}$
b) $\mathbf{X}_{i, t-1}=\mathbf{h}_{i, t-1}^{i r}=\left\{h_{i, t-1}^{L}, h_{i, t-1}^{S}, h_{i, t-1}^{C}\right\}$

The table reports coefficient estimates alongside standard errors in parentheses. Wald test reports the $\chi^{2}$-statistics of the test for the joint significance of the interest rate factors (i.e. $\beta_{1, i}=\beta_{2, i}=\beta_{3, i}=g_{1, t}=g_{2, t}=g_{3, t}=0$ ) with $p$-values reported in parentheses. *, **, $* * *$ indicate significance at the $10 \%, 5 \%$ and $1 \%$ levels, respectively. 
Table 8: Robustness check - The impact of the term structure on securitised real estate during the 1997-1998 Asian Crisis and 2007-2008 Global Financial Crisis

\begin{tabular}{|c|c|c|c|c|c|c|c|c|c|c|}
\hline & $L$ & $L^{F C}$ & Wald $L$ & $S$ & $S^{F C}$ & Wald $S$ & $C$ & $C^{F C}$ & Wald $C$ & Adj. $R^{2}$ \\
\hline US $R_{i, t}$ & $\begin{array}{l}-2.018 * \\
(1.08)\end{array}$ & $\begin{array}{l}1.589 \\
(2.31)\end{array}$ & $\begin{array}{l}-0.43 \\
(0.05)\end{array}$ & $\begin{array}{l}-1.935^{*} \\
(1.07)\end{array}$ & $\begin{array}{l}1.803 \\
(2.21)\end{array}$ & $\begin{array}{l}-0.13 \\
(0.00)\end{array}$ & $\begin{array}{l}-0.340^{* *} \\
(0.17)\end{array}$ & $\begin{array}{l}1.102 * * \\
(0.48)\end{array}$ & $\begin{array}{l}0.76^{*} \\
(2.96)\end{array}$ & 0.44 \\
\hline$I R$ in $\sigma_{U S}^{2}$ & $\begin{array}{l}1.110 \\
(0.77)\end{array}$ & $\begin{array}{l}-11.972 * * * \\
(1.64)\end{array}$ & $\begin{array}{l}-10.86^{* * * *} \\
(48.69)\end{array}$ & $\begin{array}{l}1.084 \\
(0.76)\end{array}$ & $\begin{array}{l}-12.439 * * * \\
(1.46)\end{array}$ & $\begin{array}{l}-11.35^{* * * *} \\
(77.30)\end{array}$ & $\begin{array}{l}-0.529 * * * \\
(0.13)\end{array}$ & $\begin{array}{l}2.034 * * * \\
(0.45)\end{array}$ & $\begin{array}{l}1.50 * * * \\
(15.10)\end{array}$ & \\
\hline US $h_{i, t}^{\mathbb{R}}$ & $\begin{array}{l}-5.274^{*} \\
(3.09) \\
\end{array}$ & $\begin{array}{l}0.458 \\
(9.60) \\
\end{array}$ & $\begin{array}{l}-4.82 \\
(0.29) \\
\end{array}$ & $\begin{array}{l}0.951 \\
(1.78) \\
\end{array}$ & $\begin{array}{l}-109.304 * * * \\
(33.22)\end{array}$ & $\begin{array}{l}-108.35 \text { **** } \\
(10.68)\end{array}$ & $\begin{array}{l}0.006 \\
(0.24) \\
\end{array}$ & $\begin{array}{l}24.128 \\
(6.89) \\
\end{array}$ & $\begin{array}{l}24.13 * * * \\
(12.20) \\
\end{array}$ & \\
\hline $\mathrm{AU} R_{i, t}$ & $\begin{array}{l}-1.331 \text { *** } \\
(0.29)\end{array}$ & $\begin{array}{l}0.115 \\
(0.91)\end{array}$ & $\begin{array}{l}-1.22 \\
(1.97)\end{array}$ & $\begin{array}{l}0.199 \\
(0.38)\end{array}$ & $\begin{array}{l}4.351 * \\
(2.26)\end{array}$ & $\begin{array}{l}4.55^{* * *} \\
(4.19)\end{array}$ & $\begin{array}{l}-0.261 \\
(0.16)\end{array}$ & $\begin{array}{l}-0.922 \\
(0.57)\end{array}$ & $\begin{array}{l}-1.18 * * \\
(4.59)\end{array}$ & 0.36 \\
\hline$I R$ in $\sigma_{A U}^{2}$ & $\begin{array}{l}-0.499 * \\
(0.30)\end{array}$ & $\begin{array}{l}0.925 \\
(2.06)\end{array}$ & $\begin{array}{l}0.43 \\
(0.04)\end{array}$ & $\begin{array}{l}0.737 \\
(0.53)\end{array}$ & $\begin{array}{l}-3.521 \\
(3.60)\end{array}$ & $\begin{array}{l}-2.78 \\
(0.62)\end{array}$ & $\begin{array}{l}-0.253 \\
(0.16)\end{array}$ & $\begin{array}{l}1.799^{*} \\
(0.99)\end{array}$ & $\begin{array}{l}1.55 \\
(2.57)\end{array}$ & \\
\hline $\mathrm{AU} h_{i, t}^{\mathbb{R}}$ & $\begin{array}{l}-1.348 \\
(1.10) \\
\end{array}$ & $\begin{array}{l}-19.762 * \\
(10.31)\end{array}$ & $\begin{array}{l}-21.11 * * \\
(4.36)\end{array}$ & $\begin{array}{l}0.143 \\
(0.25) \\
\end{array}$ & $\begin{array}{l}10.396 \\
(13.01) \\
\end{array}$ & $\begin{array}{l}10.54 \\
(0.65) \\
\end{array}$ & $\begin{array}{l}-0.547 * * * \\
(0.21)\end{array}$ & $\begin{array}{l}8.068 * * * \\
(5.95)\end{array}$ & $\begin{array}{l}7.52 \\
(1.59) \\
\end{array}$ & \\
\hline $\mathrm{UK} R_{i, t}$ & $\begin{array}{l}-0.389 \\
(0.59)\end{array}$ & $\begin{array}{l}2.961 \\
(2.01)\end{array}$ & $\begin{array}{l}2.57 \\
(1.78)\end{array}$ & $\begin{array}{l}-0.634 \\
(0.63)\end{array}$ & $\begin{array}{l}-1.589 \\
(2.15)\end{array}$ & $\begin{array}{l}-2.22 \\
(1.15)\end{array}$ & $\begin{array}{l}0.009 \\
(0.18)\end{array}$ & $\begin{array}{l}1.133 \\
(0.83)\end{array}$ & $\begin{array}{l}1.14 \\
(1.94)\end{array}$ & 0.33 \\
\hline$I R$ in $\sigma_{U K}^{2}$ & $\begin{array}{l}-2.724 * * * \\
(0.83)\end{array}$ & $\begin{array}{l}-7.357 \\
(5.89)\end{array}$ & $\begin{array}{l}-10.08 * \\
(3.01)\end{array}$ & $\begin{array}{l}1.016 \\
(0.91)\end{array}$ & $\begin{array}{l}-2.708 \\
(6.09)\end{array}$ & $\begin{array}{l}-1.69 \\
(0.08)\end{array}$ & $\begin{array}{l}-0.496 * * * \\
(0.18)\end{array}$ & $\begin{array}{l}-0.830 \\
(2.19)\end{array}$ & $\begin{array}{l}-1.33 \\
(0.37)\end{array}$ & \\
\hline $\mathrm{UK} h_{i, t}^{\mathbb{R}}$ & $\begin{array}{l}3.436 \\
(6.30) \\
\end{array}$ & $\begin{array}{l}-8.573 \\
(40.90) \\
\end{array}$ & $\begin{array}{l}-5.14 \\
(0.02) \\
\end{array}$ & $\begin{array}{l}-4.507 \\
(2.96) \\
\end{array}$ & $\begin{array}{l}57.100 * * \\
(26.89) \\
\end{array}$ & $\begin{array}{l}52.59 * * \\
(3.87) \\
\end{array}$ & $\begin{array}{l}0.274 \\
(0.68) \\
\end{array}$ & $\begin{array}{l}0.188 \\
(5.55) \\
\end{array}$ & $\begin{array}{l}0.46 \\
(0.01) \\
\end{array}$ & \\
\hline $\mathrm{HK} R_{i, t}$ & $\begin{array}{l}-0.205 \\
(0.34)\end{array}$ & $\begin{array}{l}0.798 \\
(0.78)\end{array}$ & $\begin{array}{l}0.59 \\
(0.69)\end{array}$ & $\begin{array}{l}-0.291 \\
(0.26)\end{array}$ & $\begin{array}{l}-0.553 \\
(0.45)\end{array}$ & $\begin{array}{l}-0.84 * * \\
(5.04)\end{array}$ & $\begin{array}{l}-0.063 \\
(0.15)\end{array}$ & $\begin{array}{l}-0.288 \\
(0.30)\end{array}$ & $\begin{array}{l}-0.35 \\
(1.95)\end{array}$ & 0.87 \\
\hline$I R$ in $\sigma_{H K}^{2}$ & $\begin{array}{l}-0.537 \\
(0.51)\end{array}$ & $\begin{array}{l}0.853 \\
(1.69)\end{array}$ & $\begin{array}{l}0.32 \\
(0.04)\end{array}$ & $\begin{array}{l}-0.465 \\
(0.34)\end{array}$ & $\begin{array}{l}1.114^{*} \\
(0.64)\end{array}$ & $\begin{array}{l}0.65 \\
(1.96)\end{array}$ & $\begin{array}{l}-0.264 \\
(0.20)\end{array}$ & $\begin{array}{l}0.901 * \\
(0.50)\end{array}$ & $\begin{array}{l}0.64 \\
(1.98)\end{array}$ & \\
\hline $\mathrm{HK} h_{i, t}^{\mathbb{R}}$ & $\begin{array}{l}0.560 \\
(0.54) \\
\end{array}$ & $\begin{array}{l}-0.909 \\
(8.94) \\
\end{array}$ & $\begin{array}{l}-0.35 \\
(0.00) \\
\end{array}$ & $\begin{array}{l}0.047 \\
(0.33) \\
\end{array}$ & $\begin{array}{l}-0.451 \\
(0.53) \\
\end{array}$ & $\begin{array}{l}-0.40 \\
(0.85) \\
\end{array}$ & $\begin{array}{l}-0.072 \\
(0.34) \\
\end{array}$ & $\begin{array}{l}1.340 \\
(1.66) \\
\end{array}$ & $\begin{array}{l}1.27 \\
(0.61) \\
\end{array}$ & \\
\hline $\mathrm{JP} R_{i, t}$ & $\begin{array}{l}-0.696 \\
(0.93)\end{array}$ & $\begin{array}{l}3.289 * * * \\
(1.13)\end{array}$ & $\begin{array}{l}2.59 * * * \\
(13.65)\end{array}$ & $\begin{array}{l}1.225 \\
(1.77)\end{array}$ & $\begin{array}{l}4.231 \\
(5.06)\end{array}$ & $\begin{array}{l}5.46 \\
(1.25)\end{array}$ & $\begin{array}{l}-0.030 \\
(0.39)\end{array}$ & $\begin{array}{l}1.787 \\
(1.43)\end{array}$ & $\begin{array}{l}1.76 \\
(1.58)\end{array}$ & 0.58 \\
\hline$I R$ in $\sigma_{J P}^{2}$ & $\begin{array}{l}3.834 \\
(4.45)\end{array}$ & $\begin{array}{l}-12.995 * * * \\
(4.43)\end{array}$ & $\begin{array}{l}-9.16^{* * * *} \\
(11.72)\end{array}$ & $\begin{array}{l}-13.844 * * * \\
(3.41)\end{array}$ & $\begin{array}{l}-32.614 \\
(21.45)\end{array}$ & $\begin{array}{l}-46.46^{* * *} \\
(4.67)\end{array}$ & $\begin{array}{l}2.820 * * * \\
(0.69)\end{array}$ & $\begin{array}{l}-0.404 \\
(5.22)\end{array}$ & $\begin{array}{l}2.42 \\
(0.22)\end{array}$ & \\
\hline $\mathrm{JP} h_{i, t}^{\mathbb{R}}$ & $\begin{array}{l}1.668 \\
(3.34) \\
\end{array}$ & $\begin{array}{c}-11.806 \\
(34.40) \\
\end{array}$ & $\begin{array}{c}-10.14 \\
(0.09)\end{array}$ & $\begin{array}{l}5.549 \\
(35.16) \\
\end{array}$ & $\begin{array}{l}660.159 \\
(592.18) \\
\end{array}$ & $\begin{array}{l}665.71 \\
(1.27) \\
\end{array}$ & $\begin{array}{c}-0.368 \\
(1.55)\end{array}$ & $\begin{array}{l}-8.837 \\
(8.74)\end{array}$ & $\begin{array}{l}-9.21 \\
(1.17) \\
\end{array}$ & \\
\hline $\mathrm{SG} R_{i, t}$ & $\begin{array}{l}-1.729 * * * \\
(0.62)\end{array}$ & $\begin{array}{l}1.710 \\
(2.13)\end{array}$ & $\begin{array}{l}-0.02 \\
(0.00)\end{array}$ & $\begin{array}{l}-1.189 * * * \\
(0.35)\end{array}$ & $\begin{array}{l}0.420 \\
(1.48)\end{array}$ & $\begin{array}{l}-0.77 \\
(0.29)\end{array}$ & $\begin{array}{l}-0.218 \\
(0.16)\end{array}$ & $\begin{array}{c}-0.661 \\
(0.68)\end{array}$ & $\begin{array}{l}-0.88 \\
(1.78)\end{array}$ & 0.67 \\
\hline$I R$ in $\sigma_{S G}^{2}$ & $\begin{array}{l}-0.962 \\
(2.33)\end{array}$ & $\begin{array}{l}-3.769 \\
(4.17)\end{array}$ & $\begin{array}{l}-4.73 \\
(1.80)\end{array}$ & $\begin{array}{l}-1.014 \\
(1.07)\end{array}$ & $\begin{array}{l}0.195 \\
(3.20)\end{array}$ & $\begin{array}{l}-0.82 \\
(0.07)\end{array}$ & $\begin{array}{l}-0.400 \\
(0.45)\end{array}$ & $\begin{array}{l}0.637 \\
(0.82)\end{array}$ & $\begin{array}{l}0.24 \\
(0.11)\end{array}$ & \\
\hline SG $h_{i, t}^{I R}$ & $\begin{array}{l}-0.215 \\
(3.30) \\
\end{array}$ & $\begin{array}{l}-0.906 \\
(3.55) \\
\end{array}$ & $\begin{array}{l}-1.12 \\
(0.91) \\
\end{array}$ & $\begin{array}{l}1.534 \\
(3.47) \\
\end{array}$ & $\begin{array}{l}0.873 \\
(4.22) \\
\end{array}$ & $\begin{array}{l}2.41 \\
(0.87) \\
\end{array}$ & $\begin{array}{c}-0.005 \\
(0.36) \\
\end{array}$ & $\begin{array}{l}0.411 \\
(1.71) \\
\end{array}$ & $\begin{array}{l}0.41 \\
(0.06) \\
\end{array}$ & \\
\hline
\end{tabular}

This table reports the results of the following GARCH model estimated over 1995-2012:

$r_{i, t}=\mu_{0, i}+\beta_{1, i} \cdot L_{i, t}+\beta_{1, i}^{F C} \cdot L_{i, t} \cdot D_{i, t}^{F C}+\beta_{2, i} \cdot S_{i, t}+\beta_{2, i}^{F C} \cdot S_{i, t} \cdot D_{i, t}^{F C}+\beta_{3, i} \cdot C_{i, t}+\beta_{3, i}^{F C} \cdot C_{i, t} \cdot D_{i, t}^{F C}+\boldsymbol{\psi} \cdot \mathbf{X}_{i, t}+\varepsilon_{i, t}$

where error term using the information set $\boldsymbol{\Omega}$ for country $i$ available at time $t-1$ is conditionally normal and heteroscedastic and expressed as $\varepsilon_{i, t}=z_{i, t} \cdot \sigma_{i, t}$ and $\varepsilon_{i, t} \mid \boldsymbol{\Omega}_{i, t-1} \sim N\left(0, \sigma_{i, t}^{2}\right) .\left\{z_{i, t}\right\}$ is a sequence of independent, identically distributed random variables zero mean and unit

variance. $r_{i, t}$ denote weekly logarithmic price changes on the domestic securitised real estate. Variables $L, S$, and $C$ are the unexpected changes in the yield curve level, slope and curvature, all calculated at time $t$ as the difference between the actual changes in the yield curve level/slope/curvature and ones forecasted via the appropriate specification of the ARMA model. Financial Crisis dummy variable $D_{i, t}^{F C}$ takes the value of one during Asian Financial Crisis of 1997-1998 and Global Financial crisis of 2007-2008. $\mathbf{X}_{i, t}$ is the vector of the control variables that include market index returns, world index returns and de-trended trading volume. The volatility equation for securitised real estate is interchangeably augmented in two alternative ways:

$$
\begin{aligned}
\sigma_{i, t}^{2}=a_{0, i}+ & a_{1, i} \cdot \varepsilon_{i, t-1}^{2}+b_{1, i} \cdot \sigma_{i, t-1}^{2}+g_{1, i} \cdot L_{i, t-1}+g_{1, i}^{F C} \cdot L_{i, t-1} \cdot D_{i, t-1}^{F C}+ \\
& +g_{2, i} \cdot S_{i, t-1}+g_{2, i}^{F C} \cdot S_{i, t-1} \cdot D_{i, t-1}^{F C}+g_{3, i} \cdot C_{i, t-1}+g_{3, i}^{F C} \cdot C_{i, t-1} \cdot D_{i, t-1}^{F C} \\
\sigma_{i, t}^{2}=a_{0, i}+ & a_{1, i} \cdot \varepsilon_{i, t-1}^{2}+b_{1, i} \cdot \sigma_{i, t-1}^{2}+g_{1, i} \cdot h_{i, t-1}^{L}+g_{1, i}^{F C} \cdot h_{i, t-1}^{L} \cdot D_{i, t-1}^{F C}+ \\
& +g_{2, i} \cdot h_{i, t-1}^{S}+g_{2, i}^{F C} \cdot h_{i, t-1}^{S} \cdot D_{i, t-1}^{F C}+g_{3, i} \cdot h_{i, t-1}^{C}+g_{3, i}^{F C} \cdot h_{i, t-1}^{C} \cdot D_{i, t-1}^{F C}
\end{aligned}
$$

The table reports coefficient estimates alongside standard errors in parentheses. The total effect of the interest rate changes during the crisis is tested using Wald tests of the form $\beta_{n, i}+\beta_{n, i}^{F C}=0$ for the price changes, and $g_{n, i}+g_{n, i}^{F C}=0$ for two alternative volatility equations respectively, with $\chi^{2}$-statistics of the tests reported in parentheses. $*, * *, * * *$ indicate significance at the $10 \%, 5 \%$ and $1 \%$ levels, respectively. 
Figure 1. Factor loadings of Nelson-Siegel using different $\lambda$ 's.

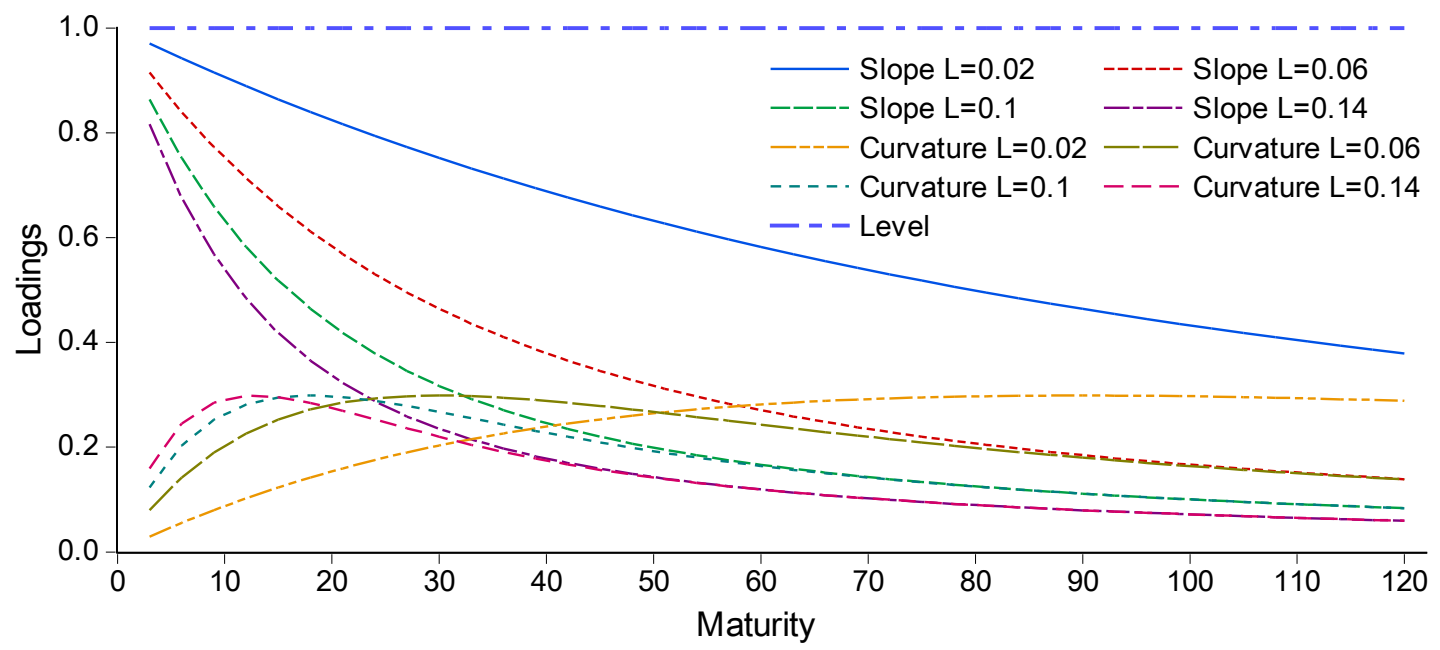


Figure 2. Yield curves for selected dates alongside fitted (model-based) counterparts
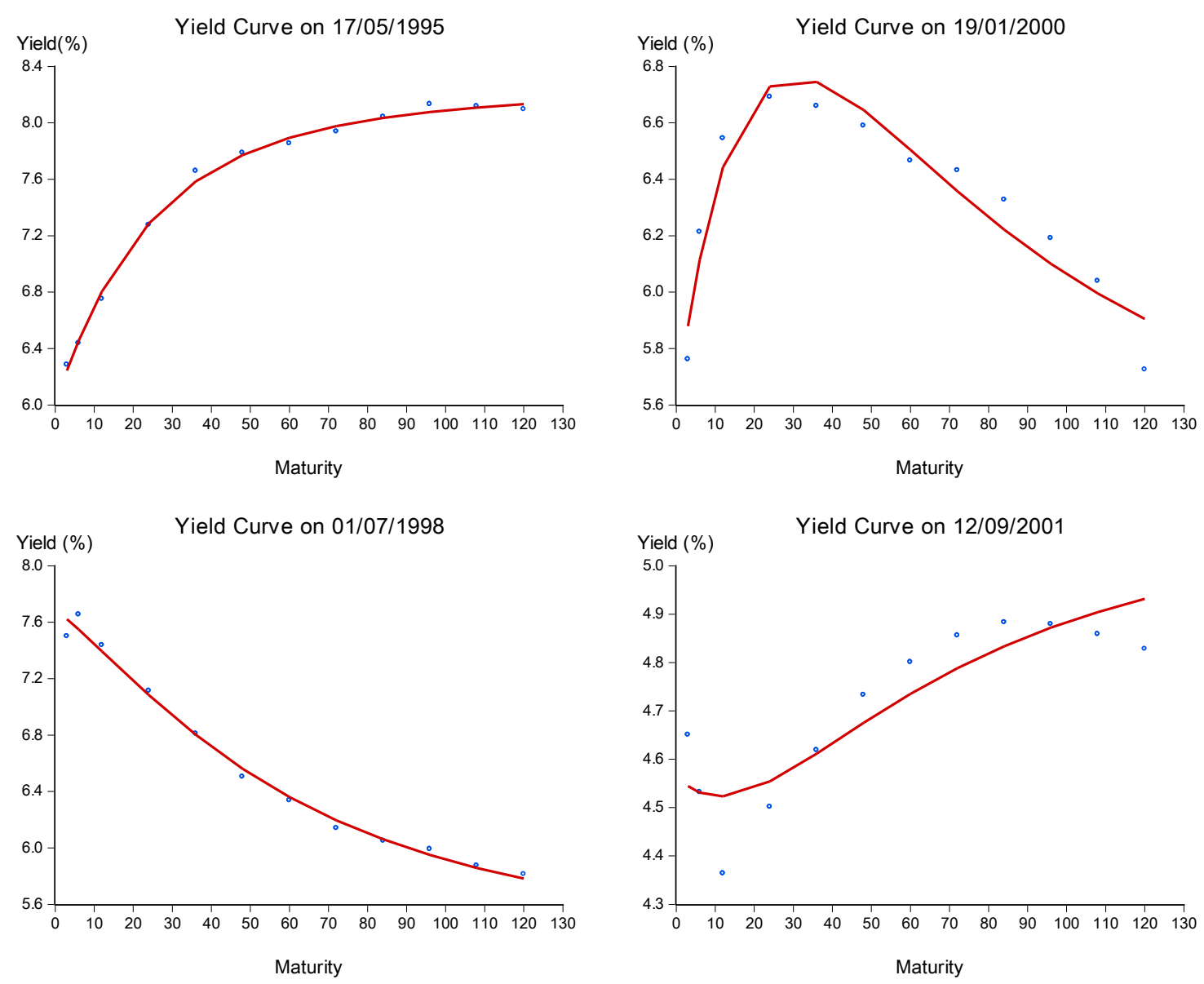
Figure 3. Evolution of the Nelson-Siegel parameters, 1995-2012
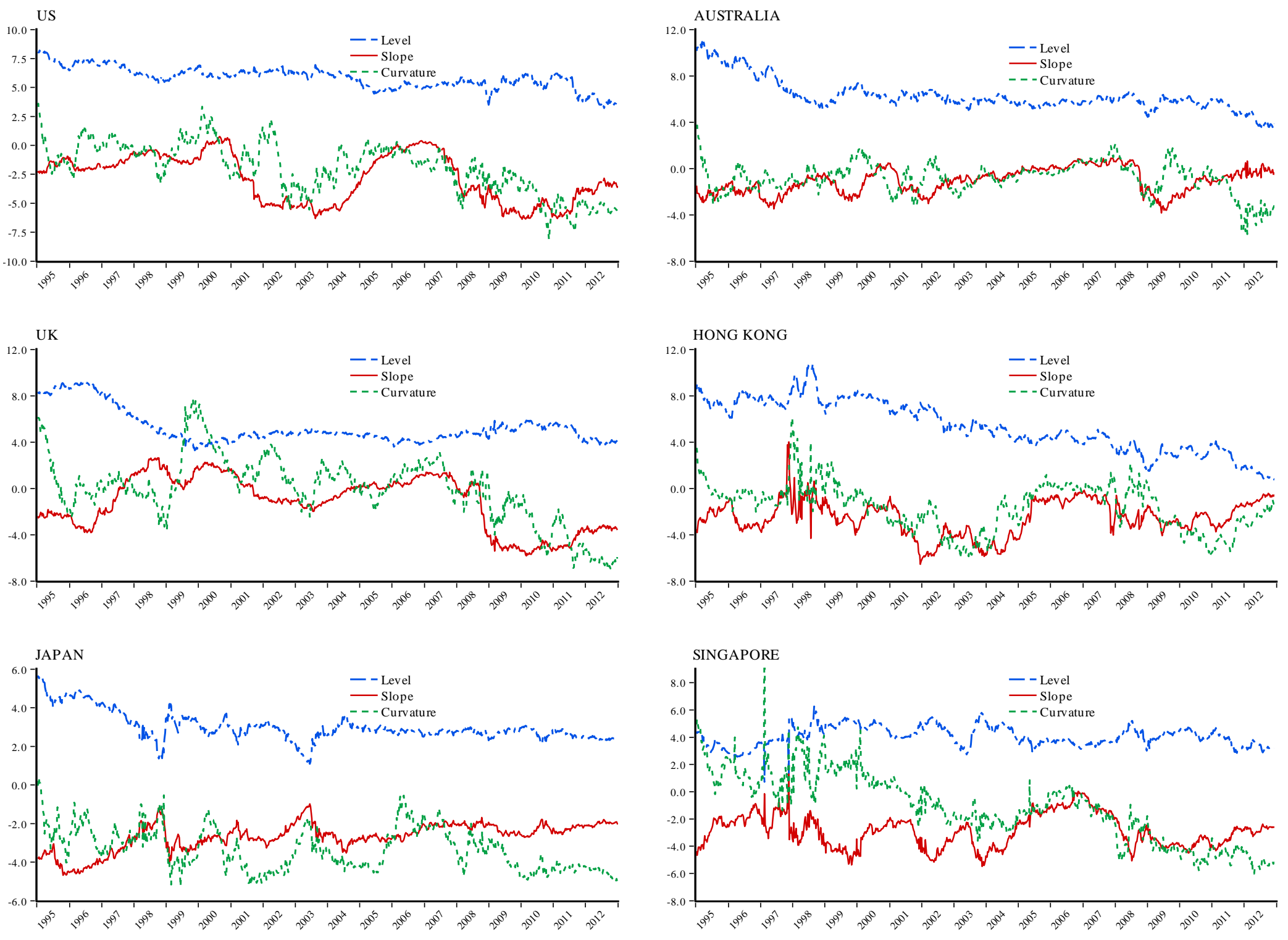
Figure 4. REIT/Property Company Leverage, 2002-2010

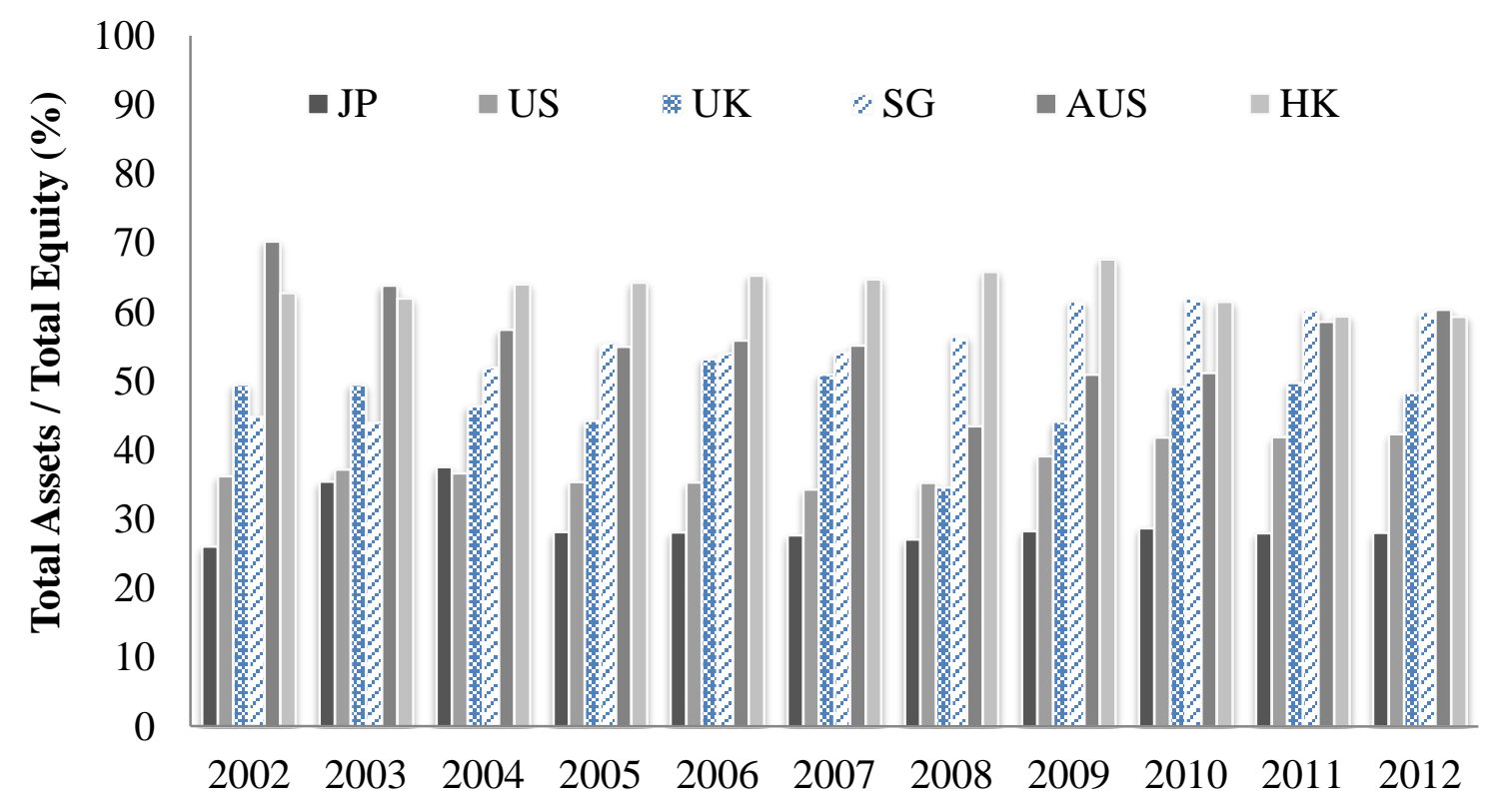

Source: SNL Financial 


\section{Endnotes:}

${ }^{\mathrm{i}}$ See for example; Chance \& Lane (1980), Flannery \& James (1984), Bae (1990), Madura \& Zarruk (1995) and Elyasiani \& Mansur (1998).

${ }^{i i}$ Plazzi et al. (2008) measures the returns dispersion in the commercial real estate sector, finding that risk changes can be explained by short-term interest rates and a variable measuring the term-spread.

iii Indeed, Litterman \& Sheinkman (1991) show that information about of large set of interest rates can be summarized using a small number of common factors. Based on a Principal Components framework, the authors identify these factors as the term structure level, steepness, and curvature.

${ }^{\text {iv }}$ See BIS paper No.25 by the Bank for International Settlements (2005).

'Bloomberg's yields on sovereign bonds are generated by the Bloomberg Fair Value (BFV) model, which utilises well-priced (liquid) bonds with similar characteristics such as issuer, creditworthiness, and embedded options. Our sample utilises government issued securities which are option-free. The model also excludes same sector bonds with significantly higher or lower z-spreads. Therefore, concerns regarding thin trading is minimized for our sample.

${ }^{\text {vi }}$ It should be noted that the variation of the Nelson-Siegel model used in this study assumes a constant $\lambda$ parameter across time. Our approach closely follows the intuition of Diebold \& Li (2006), where $\lambda$ is set to be linked to the medium-term interest rate maturity (e.g. 30 months). One can estimate the model with a time-varying $\lambda$ similar to Koopman et al. (2010). However, if one employs a time-varying $\lambda$ as a fourth latent factor, the medium-term parameter (curvature) would be no longer linked to the observable medium-term maturity. To avoid introducing an additional time-varying component in the yield-curve model we opt to use the fixed $\lambda$ model specification.

${ }^{\text {vii }}$ In an earlier version of the paper we estimated the model using the approach of Diebold \& $\mathrm{Li}$ (2006), assuming a consistent decay parameter of 0.0609 . Both specifications yield statistically identical results with regard to the relation between the Nelson-Siegel factors and securitised real estate markets. However, we felt that the selection approach provides a greater degree of confidence in the individual country's results. The results from the earlier version of the paper are available from the authors upon request.

viii e.g. Flannery \& James (1984); Bae (1990); Madura \& Zarruk (1995); Faff \& Howard (1999).

${ }^{\text {ix }}$ See also papers such as Dinenis \& Staikouras (1998) who consider five alternative models to estimate unexpected interest rate changes.

${ }^{x}$ An earlier version of this paper used data from SNL Financial for the U.S. and Thomson Reuters Datastream for the remaining markets. The results appear to be robust and are not dependent on the choice of index provider. These findings support those of Serrano \& Hoesli (2009) who report high average correlations between the main providers of listed real estate indices. Serrano \& Hoesli (2009) examined the 1990 to 2007 period and examined indices produced by FTSE/EPRA NAREIT, Thomson Reuters Datastream, GPR and S\&P/Citigroup.

${ }^{x i}$ This figure may be increased to as high as $60 \%$ if certain conditions, such as credit ratings being obtained, are met.

${ }^{\text {xii }}$ In part due for the sake of brevity, we do not report the results for the mean equation from the augmented volatility GARCH models. The results are very similar to those obtained with the base fourfactor GARCH model reported in Table 3 and previously discussed. The complete results are available from the authors on request. 
xiii The use of sign dummies in interaction with the yield curve factors resolves the multicollineary problem commonly associated with the use of dummy variables. 